\title{
TRASFORMACIONES DEMOGRÁFICAS, INDEPENDENCIA RESIDENCIAL Y VULNERABILIDAD EN LOS HOGARES DE LOS MAYORES EN BARCELONA
}

\author{
Cristina López-Villanueva \\ Universitat de Barcelona \\ clopez@ub.edu \\ ORCID iD: https://orcid.org/0000-0002-7676-0765 \\ Miguel Rubiales Pérez \\ Universitat de Barcelona \\ mrubiales@ub.edu \\ ORCID iD: https://orcid.org/0000-0002-7364-2448 \\ Isabel Pujadas-Rúbies \\ Universitat de Barcelona \\ ipujadas@ub.edu \\ ORCID iD: https://orcid.org/0000-0001-7579-6603
}

Recibido: 15/03/2021; Aceptado: 26/11/2021; Publicado: 20/01/2022

\begin{abstract}
Cómo citar este artículo/citation: López-Villanueva, Cristina; Rubiales Pérez, Miguel y Pujadas-Rúbies, Isabel (2021). Trasformaciones demográficas, independencia residencial y vulnerabilidad en los hogares de los mayores en Barcelona. Estudios Geográficos, 82 (291), e086. https://doi.org/10.3989/estgeogr.202197.097
\end{abstract}

RESUMEN: El envejecimiento de la población sitúa las formas de residencia de los mayores en un primer plano. En las dos últimas décadas los hogares de las personas de edad han protagonizado grandes transiciones. Las principales dinámicas reflejan una reducción del tamaño del hogar y un aumento de la independencia residencial que se manifiesta en una proporción creciente de mayores que comparten el hogar con su pareja o cónyuge o bien que residen en solitario; mientras que disminuye la proporción de personas que viven en hogares intergeneracionales.

Sin embargo -pese a la constatación de la independencia residencial a edades cada vez más avanzadas- la creciente presencia de personas que viven solas y con menos familiares o allegados en las grandes áreas urbanas puede incidir en un incremento de la situación de vulnerabilidad de los mayores. La condición de edad avanzada puede ir asociada a ciertas desventajas como la falta de ingresos, insuficientes condiciones de habitabilidad, limitaciones en la actividad cotidiana, afectaciones en el estado de salud, aislamiento o soledad.

El objetivo de este trabajo es presentar la evolución de los tipos de hogares en la vejez y estudiar la relación existente entre la tipología de hogares de los mayores y su papel en la incidencia de vulnerabilidad en la ciudad de Barcelona, para ello se realiza un análisis partir de tablas de contingencia y de la corrección mediante $V$ de Cramer de los valores Ji cuadrado. El análisis se lleva a cabo para la explotación de los microdatos de la Encuesta Sociodemográfica de Barcelona realizada por el Ayuntamiento de Barcelona en 2017.

PALABRAS CLAVE: tipología de hogares, envejecimiento demográfico, características sociodemográficas de los mayores, vulnerabilidad, Barcelona.

\section{Sociodemographic transformations, residential in dependence and vulnerability in the ho useholds of the elderly in Barcelona}

ABSTRACT: Population ageing brings the forms of residence of elderly people to the foreground. The homes of elderly people have undergone major transitions in the last two decades. There has been a reduction in household size and an increase in residential independence. Indeed, there is a growing proportion of older people who share a home with their partner or spouse, or who reside alone. Therefore, the proportion of people living in intergenerational households decreases.

In large cities, the population above the age of 64 is now more present in one-person and single-parent households, and less in simple nuclear ones. However, the fact that residential independence at increasingly advanced ages is being confirmed has also its downside. As more elderly people live alone and with fewer relatives or close friends, there can be an increase in elderly frailty. The condition of advanced age can be associated with certain disadvantages such as lack of income, insufficient living conditions, limitations in daily activity, effects on the state of health, isolation or loneliness.

The main aim of this research is to study the composition of elderly households in the city of Barcelona, relating it with the household's characteristics, its economic conditions, and the perception of the state of health of its residents. Using a Ji square corrected by V of Cramer tables, an analysis on the vulnerability dimensions is pointed out. Microdata from the Sociodemographic Survey for Barcelona carried out by the local government in 2017, are used for the analysis.

KEY WORDS: typology of households, demographic ageing, sociodemographic characteristics of the elderly, vulnerability, Barcelona. 


\section{INTRODUCCIÓN}

El envejecimiento demográfico sitúa las formas de residencia de los mayores en un primer plano y éstas se convierten en un ineludible objeto de estudio. Los hogares de las personas de edad (mayores de 65 años) han protagonizado en las últimas décadas grandes cambios, han aumentado su presencia y diversificado su estructura y su composición. Ello se manifiesta en una creciente independencia residencial a edades avanzadas (Doblas, 2018).

Los elementos que intervienen en estas transformaciones afectan a las poblaciones de los países desarrollados: el aumento de la esperanza de vida a edades avanzadas, la sobremortalidad masculina ahora en retroceso, las mejoras en las condiciones de salud y de vida de los mayores (Pérez y Abellán, 2018) y la forma en que diferentes eventos -como el matrimonio o la cohabitación (De Jong Gierveld, 2004); la ruptura de las uniones; el número de hijos o la infecundidad (Reher y Requena, 2017 y 2018)- afectan al curso de vida y tienen un impacto en las formas de hogar al final de la vida. Junto a estos factores, propios de la Segunda Transición Demográfica (Van de Kaa, 1987), cabe tener en cuenta otros elementos que contribuyen a explicar esta independencia residencial: la generalización de las pensiones de jubilación o la elevada proporción de mayores propietarios de su vivienda.

Las dinámicas de los hogares de los mayores presentan una tendencia a la convergencia entre los países europeos $y$, aunque con puntos de partida distintos, se concretan en la reducción del tamaño del hogar, el aumento de personas de edad que comparten el hogar con su pareja o cónyuge y de los que residen en solitario, así como la disminución de la proporción de personas que viven en hogares intergeneracionales de mayor complejidad.

Sin embargo, a pesar de la tendencia creciente a la autonomía residencial de las personas de edad, ello no es siempre sinónimo de bienestar o de una situación digna y adecuada (Lebrusán, 2019). Las características y condiciones de la vivienda, la situación económica y el estado de salud son, entre otros, los principales elementos que hacen vulnerables los hogares de los mayores. El objetivo de este trabajo es, pues, estudiar la relación existente entre la tipología de hogares de los mayores y su papel en el proceso de vulnerabilidad.

El concepto de vulnerabilidad es amplio y presenta diversos enfoques de análisis. El Departamento de Asunto Económicos y Sociales de Naciones Unidas (DAES), en su informe sobre la situación social del mundo del año 2003, definía el concepto de vulnerabilidad como un estado de elevada exposición a determinados riesgos e incertidumbres, combinado con una capacidad disminuida para protegerse o defenderse de ellos y hacer frente a sus consecuencias negativas (citado en De Cos y Usobiaga, 2019). En este sentido, la vulnerabilidad comprende dos componentes: por un lado, el incremento de los riesgos que afectan a las personas y a los hogares y, por otro, el debilitamiento de la capacidad para hacerles frente.

Diversas han sido las propuestas de articulación para el estudio de la vulnerabilidad de los hogares (Filgueira y Fuentes, 1999; Perona y Rocchi, 2001; Ruiz Rivera, 2012; Villa y Rodríguez Vignoli, 2002) en el caso de América Latina o (Lechuga, Martínez y Carmona, 2011) para el caso de España. Así como numerosas han sido las propuestas de construcción de índices de vulnerabilidad social según los distintos campos de conocimiento; desde el trabajo pionero de Cutter, Bryan, Boruff y Lynn (2003) adaptado a los peligros ambientales o la obra de Spielman, et al., (2020) sobre los criterios de su aplicación. En el caso de España existen diversos trabajos en los cuales se realiza un esfuerzo por formular un índice de vulnerabilidad (Gómez y Hernández Aja, 2021; Universidad Carlos III, 2019). A nivel local, algunos trabajos recientes se han realizado en el ámbito de la provincia de Barcelona (Diputació de Barcelona, 2019) o en la Región Metropolitana (Ruiz et al., 2020).

La noción de vulnerabilidad, como se ha mencionado, es extensa y compleja y se refiere al proceso por el cual se está en riesgo de engrosar el espacio de exclusión (Castel, 1991). La vulnerabilidad está constituida por condiciones de desfavorecimiento y desventaja de las personas y de los hogares que quedan expuestas a sufrir cambios en sus condiciones de vida comprometiendo su bienestar (Perona y Rocchi, 2001). En este sentido, diversas son las dimensiones desde las cuales abordar el análisis de la vulnerabilidad como múltiples son los planteamientos (Fordham, Lovekamp, Thomas y Phillips, 2013; Kaztman, 2000) que se resumen en los siguientes ámbitos: a) los sociodemográficos, entre los cuales se incluiría el envejecimiento -y por tanto la edad-, el género o la aloctonía; b) los residenciales, entre los cuales figurarían las características y las condiciones de la vivienda como el régimen de tenencia, la antigüedad o la accesibilidad; c) los socioeconómicos, entre los cuales se encontrarían las condiciones del empleo -no en el caso de este trabajo puesto que se centra en el estudio de los mayores-, la renta o el nivel de instrucción como proxy de la situación 
socioeconómica; d) los relacionados con el estado de salud -sobre todo entre los mayores- y la necesidad de ayuda para las tareas cotidianas; y e) los relacionales, entre los cuales se contemplan las redes de relaciones sociales familiares, vecinales o comunitarias.

El objetivo de este trabajo es determinar, entre todas estas dimensiones, hasta qué punto la tipología del hogar y, por tanto, con quien se convive, condiciona el nivel de vulnerabilidad de la población mayor.

En el contexto del envejecimiento demográfico y de las transiciones experimentadas por los hogares de los mayores, especialmente de los países desarrollados, cabe tenerse en cuenta los siguientes antecedentes para comprender su actual evolución.

En primer lugar, el aumento de la esperanza de vida, que no ha cesado de crecer durante los siglos XX y XXI -a excepción del lapso producido por la pandemiaasí como la diferencia de vida media entre hombres y mujeres. Esta brecha explicaría el crecimiento de mujeres viudas en hogares unipersonales a edades avanzadas y en hogares monoparentales y ello constituiría una condición de vulnerabilidad. La reducción reciente de la diferencia de esperanza de vida entre hombres y mujeres (Meslé, 2006) ha favorecido un menor crecimiento de hogares unipersonales y un aumento de las personas mayores que viven en pareja (Rogero, 2015) dilatando la duración del nido vacío. Esta prolongación no significa un menor riesgo de vulnerabilidad si se tiene en cuenta que algunos de los trabajos más recientes muestran que el aumento de esperanza de vida en España no ha ido necesariamente unida a un período libre de enfermedad (Zueras y Rentería, 2021).

En segundo lugar, la reducción de la fecundidad, acompañada de un incremento de la infecundidad (Esteve, Devolder y Domingo, 2016; Esteve y Treviño, 2019; Kreyenfeld y Konietza, 2017). El tipo de hogar durante la vejez está fuertemente relacionado con la historia reproductiva de las mujeres produciéndose una asociación significativa entre la infecundidad y vida en solitario, de la misma manera que aumenta la probabilidad de convivencia con descendientes al aumentar el número de hijos (Reher y Requena, 2017).

En tercer lugar, la ruptura de las uniones. En España están llegando a la vejez las generaciones que protagonizaron los cambios de la Segunda Transición Demográfica. Mayores divorciados y separados conforman hogares en solitario o monoparentales, algunos trabajos revelan el riesgo de vulnerabilidad, especialmente entre las mujeres (Choi, 1996).
Otros tipos de condicionantes, como la generalización de la protección social a los mayores, y entre ellas, las pensiones de jubilación han influido en la independencia residencial de las personas de edad. Sin embargo, la asignación y la tipología de estas pensiones dependen de la historia contributiva de los individuos y ello ha generado desigualdades puesto que algunos de los mayores han experimentado relaciones laborales complejas que no les han permitido gozar de manera completa de este derecho. Esta situación afecta más a las mujeres y sobre todo a las viudas (Lebrusán, 2019).

La vivienda en propiedad como régimen de tenencia generalizado entre los mayores, ancla la población en el hogar, actúa como bien que asegura la vejez (Leal y Martínez del Olmo, 2017) y como elemento que garantiza la independencia residencial. A pesar de ello, las condiciones de algunas viviendas de las personas de edad presentan deficiencias o inadecuación a las nuevas necesidades; la antigüedad del parque hace aflorar situaciones de degradación ante las cuales, una vez adquirida la condición de pensionistas, se hace más difícil ponerle remedio.

La reducción del tamaño de los hogares en la vejez por emancipación de los hijos y, a edades más avanzadas por deceso de la pareja, incrementa el número de personas que viven solas (López-Villanueva y Pujadas, 2018a; 2018b). La soledad, junto al descenso del nivel de renta por viudedad sobre todo en las mujeres, la presencia de problemas de salud física y/o mental y la distancia residencial respecto a familiares o allegados; sitúa en una condición de fragilidad a los mayores, que tienden a un replegamiento en el hogar y a reducir sus relaciones. La mayor presencia en hogares no tradicionales, con un menor número de convivientes y menos familiares pueden incrementar la vulnerabilidad de los hogares de los mayores.

La situación de fragilidad puede intensificarse en los grandes espacios urbanos donde la densidad de las relaciones sociales puede ser más débil y más cambiante por el efecto de la rápida transformación urbana. Ello puede conducir al aislamiento y a la inseguridad en algunos barrios de las grandes ciudades (Fernandez-Carro y Evandrou, 2014) e incrementar la vulnerabilidad física, social, emocional y ambiental (Sánchez-González, 2009). Contrariamente, el apego a un entorno y a una vivienda percibidos como conocidos y propios favorecen la autoestima, la seguridad, la salud, la calidad de vida, y refuerzan la identidad (Cairney y Boyle, 2004; Costa-Font, Elvira y Mascarilla-Miró, 2009; Deci y Ryan, 2008; Rojo-Pérez, Fernández-Mayoralas y Lardiés-Bosque, 2012; Weinstein et al., 2019). 
La independencia residencial se transforma, pues, en dilema en el proceso de envejecimiento (Lebrusan, 2019): por un lado, los beneficios de la vida independiente; por otro, las dificultades para atender diferentes niveles de dependencia en su dimensión física y/o social relacionada con los elementos de la vivienda y el entorno (Mitchell y Kemp, 1996). La vulnerabilidad de los mayores puede aparecer tanto por la pérdida del propio hogar, como por su mantenimiento sin los recursos y cuidados necesarios para superar las crecientes barreras físicas, de la vivienda y del entorno.

Este trabajo profundiza en la relación existente entre la tipología de hogares y las diferentes dimensiones de vulnerabilidad atendiendo a las características demográficas, residenciales, económicas y de salud. Con ello se pretende aportar elementos de reflexión a la relación existente entre la diversidad de tipos de hogar de las personas mayores y su papel en el proceso de vulnerabilidad en el caso aplicado a la ciudad de Barcelona.

\section{FUENTES Y MÉTODOS}

La fuente principal utilizada para la realización de este trabajo son los microdatos de la Encuesta Sociodemográfica de Barcelona (ESDB) realizada por la Dirección General de Planificación e Innovación y la Oficina Municipal de Datos del ayuntamiento de esta ciudad, en 2017. La encuesta permite analizar con detalle las condiciones de la vivienda, las características demográficas, socioeconómicas y la percepción del estado de salud de la población. Además, supone una actualización temporal de resultados, más recientes que los de la última operación censal. Junto a esta fuente, también se han trabajado las estadísticas padronales de Barcelona y el censo de 2001 para tratar la evolución del proceso de envejecimiento y las transformaciones de los hogares.

El artículo se estructura en tres partes: En primer lugar, se han analizado las dinámicas demográficas que condicionan el envejecimiento en la ciudad de Barcelona a partir de los datos padronales de 2006 y 2020 y datos censales de 1991 y 2001 proporcionados por el Departamento de Estadística del Ayuntamiento de Barcelona.

En segundo lugar, se ha estudiado la estructura y la composición de los hogares de los mayores de 65 años según el sexo, la edad y el estado civil; la fuente ha permitido realizar una aproximación general a nivel de distrito. Se ha recodificado la tipología del hogar en 5 tipos atendiendo al número y tipo de núcleo adaptando el modelo de Hammel y Laslett (1974): 1) unipersonales, 2) parejas con hijos, 3) parejas sin hijos, 4) monoparentales y 5) complejos (extensos, múltiples, sin núcleo). Con la finalidad de obtener una imagen evolutiva se han comparado los microdatos de la ESDB con los del censo de 2001. En esta parte se ha representado la tipología de hogares de mayores según los distritos de la ciudad calculando el cociente de localización, que expresa el grado de concentración de cada tipo de hogar en el distrito en relación con el promedio de la ciudad.

En tercer lugar, se han analizado una serie de variables que condicionan la vulnerabilidad de los mayores; siguiendo las dimensiones citadas en el apartado anterior: a) En referencia al ámbito sociodemográfico se han utilizado las variables de edad, sexo, estado civil y aloctonía; b) En relación con el ámbito residencial se han analizado variables relacionadas con el régimen de tenencia, la antigüedad de la vivienda, las dotaciones mínimas (calefacción); c) En referencia al ámbito socioeconómico no se han utilizado las variables de las condiciones de empleo puesto que la población que se estudia es la mayor de 65 años, se ha considerado el nivel de instrucción como proxy de posición social; la renta de hogar y capacidad de gasto y; d) En relación con el ámbito de salud se han analizado las variables relacionadas con la percepción subjetiva de salud y las limitaciones para realizar actividades habituales.

Todas estas variables se han analizado según el tipo de hogar y el riesgo de pobreza calculado por una variable de la propia encuesta.

El análisis de las asociaciones entre variables utiliza tablas de contingencia y la prueba de Ji cuadrado para comprobar la dependencia o independencia de las variables. El test de Ji cuadrado es una de los estadísticos más útiles y empleados para la comprobación de hipótesis cuando las variables son nominales. Su principal problema es la sensibilidad a los grandes números de observaciones y su incapacidad para determinar el nivel de asociación entre variable, cuando está existe. Esto se palía empleando el test de V de Cramer, capaz de cuantificar la intensidad de la asociación entre dos variables de una tabla de contingencia. Además, el test de $\mathrm{V}$ de Cramer es una medida sólida respecto a la distribución de los datos, rápida de calcular y ampliamente aceptada por la comunidad científica (McHugh, 2013). Las variables seleccionadas para los cruces con todas las demás son las formas de hogar y el riesgo de pobreza. El tipo de hogar se ha seleccionado por su capacidad para dar respuesta a las principales pre- 
guntas del apartado. Es decir, el papel que juegan las formas de convivencia de las personas mayores en la calidad de vida y los procesos de vulnerabilidad. La otra gran variable para la realización de cruces es el riesgo de pobreza. Se selecciona por ser la variable más central en las dinámicas y procesos de vulnerabilidad. A pesar de los diferentes sistemas de protección social, la capacidad de acceso al mercado para solucionar las necesidades resulta un elemento determinante no solo del bienestar material directo, también con frecuencia del estatus y la consideración en diferentes redes sociales y familiares. El riesgo de pobreza se ha preferido frente las otras medidas sintéticas de vulnerabilidad como la intensidad del trabajo - porque la población objetivo del análisis está mayoritariamente jubilada- o como la pobreza material severa -que da cuenta de una situación de pobreza más intensa, pero que afecta a menos personas-. El resto de variables asociadas al proceso de vulnerabilidad y que aparecen en la encuesta, como la privación de algún elemento concreto, las condiciones de salud deteriorada, la dependencia o las condiciones de la vivienda, son aspectos relevantes en los procesos de vulnerabilidad, pero parciales por lo que pierden sentido en la mayoría de cruces con otras variables.

\section{RESULTADOS Y DISCUSIÓN}

\section{Dinámicas demográficas y proceso de envejecimien- to en la ciudad de Barcelona}

El trabajo se circunscribe a la ciudad de Barcelona, intensamente envejecida, lo que le otorga aun mayor relevancia al estudio de los hogares de los mayores.

Para entender la estructura de los hogares de las personas de edad en la ciudad se hace necesario explicar cuál ha sido la dinámica demográfica y los procesos que han modelado su estructura por edades. Cuatro grandes dinámicas han configurado esta evolución: a) una evolución positiva de la esperanza de vida y un aumento de la supervivencia a edades avanzadas; b) la caída y persistencia de una fecundidad muy reducida (Pujadas, Bayona-i-Carrrasco, GilAlonso y López-Villanueva, 2013); c) una migración residencial desde la ciudad hacia su periferia metropolitana (Garcia-Coll, López-Villanueva y Pujadas, 2016; Bayona-i-Carrasco y Pujadas, 2014) y d) la importancia de una migración internacional desde finales del s. XX (Domingo, Galeano y Bayona-i-Carrasco, 2021). Estos procesos han transformado la estructura por edades de la población y también la composición de los hogares (López-Villanueva, 2008).

\section{Evolución positiva de la esperanza de vida y aumento de la supervivencia a edades avanzadas.}

La esperanza de vida de Barcelona ha seguido una evolución alcista de forma continua, con incrementos a edades avanzadas. Entre 1980 y 2000 la esperanza de vida al nacer de los varones aumentó de 73,8 a 76,3 y alcanza los 81 años en 2019 (Ayuntamiento de Barcelona e INE); para la población femenina la ampliación es aún más importante al pasar de 79,5 a 83,2 y 86,4 años respectivamente. Este incremento es igualmente notorio entre los mayores de 65 años cuya esperanza media de vida ha subido de 14,8 a 19,5 años para los varones y de 18,1 a 23,6 años para las mujeres entre 1980 y 2019. Las consecuencias son, pues, una mayor presencia de población mayor y anciana en la cúspide de la pirámide que incidirá en el crecimiento del número de hogares y cambiará su estructura y composición generando un aumento de hogares unipersonales y de parejas sin hijos y manteniendo la presencia de hogares complejos (extensos, múltiples y sin núcleo).

\section{Persistencia de una fecundidad muy reducida}

Desde finales de los años setenta comienza un nuevo ciclo demográfico que pone fin a la alta natalidad y a las generaciones del baby boom e invierte tendencias anteriores, mostrando la profundidad de los cambios sociodemográficos que se han identificado bajo el nombre de la Segunda Transición Demográfica (Van de Kaa, 1987). Muy lejos quedan las cifras de 30.000 nacimientos anuales de los años setenta, las cifras más altas alcanzadas. En tiempo récord, los nacimientos se habían reducido a la mitad, 15.190, en 1985, y continuaron a la baja hasta alcanzar la cifra mínima de 12.000 nacimientos anuales a mediados de los años noventa. La reducción de la fecundidad incide en una reducción del número de miembros en el hogar y en las formar de convivencia al final de la vida (Reher y Requena, 2018).

\section{Migración residencial y suburbanización}

Más allá del crecimiento natural, la migración residencial desde la ciudad hacia su periferia metropolitana ha jugado un papel importantísimo en la reconfiguración residencial y ha tenido un potente impacto sobre la estructura de la población. Barcelona, a partir de 1975 inició una etapa de desconcentración caracterizada por las dinámicas de suburbanización protagonizadas por una movilidad residencial de población joven en el momento de formación o ampliación familiar desde la capital hacia otros municipios de su 
periferia metropolitana (Pujadas, 2009). El proceso de suburbanización tuvo un impacto sobre la configuración de los hogares tanto en el centro de las ciudades como en sus periferias residenciales dando lugar a una especialización territorial de los mismos. El centro se especializó en hogares más reducidos y "menos familiares" mientras que las coronas metropolitanas que habían experimentado un fuerte crecimiento se distinguieron por su elevada concentración de hogares nucleares de parejas con hijos (López-Villanueva y Pujadas, 2011); aunque no cabe desdeñarse la movilidad de los mayores (Pujadas, Bayona-i-Carrasco y Rubiales, 2016).

\section{Importancia de la migración internacional}

La inmigración internacional marca, desde finales del siglo XX, un nuevo ciclo demográfico en Barcelona. El crecimiento de la población se modifica de nuevo a favor de cierta recuperación de Barcelona y de las grandes ciudades de su área metropolitana debido al peso de la inmigración extranjera que se concentra principalmente en las grandes urbes. En Barcelona la población nacida en el extranjero crece rápidamente $3,2 \%$ en $1991 ; 8,3 \%$ en $2001 ; 21,5 \%$ en 2011 y supera el $27,8 \%$ en 2020 (Tabla 1), mostrando una de las proporciones más altas de todas las ciudades españolas. La intensidad de estos flujos ha contribuido a frenar el proceso de envejecimiento y por lo tanto a rejuvenecer la estructura por edades. Barcelona ha experimentado un aumento significativo de la población jovenadulta entre 20 y 40 años y un ligero aumento de la población infantil. En consecuencia, la proporción de población mayor de 65 años disminuyó ligeramente.

La migración extranjera es diversa en edades, procedencias y nacionalidades y afecta de manera diferente a la composición de los hogares; en el momento inicial de la llegada se produjo un crecimiento de los hogares sin núcleo, extensos y múltiples propios de las primeras etapas de la migración (Domingo y Bayona-i-Carrasco, 2010); después, la consolidación de los flujos y la reagrupación familiar ha contribuido a la creación de hogares familiares. El origen podría

TABLA 1

INDICADORES DEMOGRÁFICOS. BARCELONA. 1991-2020

\begin{tabular}{|c|c|c|c|c|c|c|}
\hline Indicadores demográficos, Barcelona 1991-2020 & 1991 & 2001 & 2006 & 2011 & 2017 & 2020 \\
\hline POBLACIÓN TOTAL & 1.643 .542 & 1.503 .884 & 1.629 .537 & 1.615 .985 & 1.625 .137 & 1.666 .530 \\
\hline Población 65 años y más & 285.481 & 325.859 & 334.101 & 336.891 & 349.132 & 352.299 \\
\hline \% población menor de 15 años & 14,4 & 11,5 & 11,7 & 12,3 & 12,7 & 12,3 \\
\hline$\%$ población de 15 a 64 años & 68,2 & 66,8 & 67,8 & 66,8 & 65,8 & 66,5 \\
\hline \% mayores (65 años y más) & 17,4 & 21,7 & 20,5 & 20,8 & 21,5 & 21,1 \\
\hline \% población nacionalidad extranjera & 1,4 & 6,3 & 16,5 & 17,3 & 17,8 & 21,7 \\
\hline \% población nacida en el extranjero & 3,2 & 8,3 & 19,7 & 21,5 & 23,7 & 27,8 \\
\hline \% mayores de nacionalidad extranjera (65 años y más) & 0,1 & 0,2 & 0,4 & 0,4 & 0,6 & 0,7 \\
\hline Edad media de la población & 40,7 & 43,6 & 43 & 43,4 & 44 & 43,9 \\
\hline Edad media de la población femenina & 42,6 & 45,6 & 45 & 45,4 & 45,7 & 45,7 \\
\hline Edad media de la población masculina & 38,5 & 41,4 & 40,8 & 41,3 & 42 & 41,9 \\
\hline Índice de envejecimiento (Mayores65 /Menores15 años) & 109,2 & 175,9 & 165,2 & 159,9 & 159,7 & 161 \\
\hline Índice de envejecimiento femenino & 140,1 & 220,6 & 206,3 & 199,1 & 197,1 & 198,6 \\
\hline Índice de envejecimiento masculino & 80,1 & 133,2 & 125,8 & 122,8 & 124,2 & 125,5 \\
\hline
\end{tabular}

\begin{tabular}{|c|c|c|c|c|c|c|}
\hline Ocupación media del hogar (personas / domicilio) & 2,8 & 2,5 & 2,5 & 2,5 & 2,5 & 2,5 \\
\hline$\%$ domicilios de una sola persona & 18,1 & 26,2 & 29,4 & 31 & 30,9 & 30,9 \\
\hline$\%$ domicilios de cuatro personas & 20,3 & 16,3 & 14,1 & 13,3 & 13,7 & 13,6 \\
\hline \% población que vive sola & 6,4 & 10,3 & 11,5 & 12,6 & 12,5 & 12,3 \\
\hline \% Población mayor 65 años que vive sola (total) & 18,9 & 23,2 & 24,6 & 25,7 & 25,7 & 25,7 \\
\hline \% Población femenina mayor 65 años que vive sola & 25,6 & 30,9 & 32,1 & 33,1 & 32,7 & 32,5 \\
\hline \% Población masculina mayor 65 años que vive sola & 8 & 11 & 12,7 & 14,2 & 15,1 & 15,4 \\
\hline
\end{tabular}

Fuente: Departamento de Estadística, Censo 1991 y 2001, Padrón continuo 1 de enero de 2006 a 2020, Ajuntament de Barcelona. Nota: los indicadores en \% se han calculado sobre el total de población de Barcelona de cada año. 
convertirse en un elemento de vulnerabilidad. Puesto que la migración internacional data de principios del s. XXI, los protagonistas de esta migración no han alcanzado todavía edades avanzadas.

El envejecimiento de la población de Barcelona tiene un rostro marcadamente femenino, la edad media es superior a la masculina, como también la proporción de mayores, el índice de envejecimiento y sobre todo la proporción de mujeres que viven solas que duplica la proporción de varones de $32,5 \%$ a $15,4 \%$ en 2020 . A pesar de ello las diferencias tienden a disminuir.

\section{Hogares y curso de vida. Independencia residencial de los mayores.}

La composición de los hogares en la ciudad de Barcelona muestra la estructura envejecida de su población como consecuencia de las dinámicas anteriormente descritas (López-Villanueva, Pujadas y Rubiales, 2019). La edad avanzada unida a las características individuales de las personas, las condiciones de la vivienda o el estado y la percepción de la salud pueden situar, como se ha explicado, en una condición de vulnerabilidad a las personas mayores. Esta situación se puede ver agravada por el hecho de residir en una gran urbe como puede ser la ciudad de Barcelona donde la densidad y el tipo de relaciones puede ser cambiante por la rápida transformación urbana en algunos barrios, sobre todo en un momento de replegamiento ocasionado por la vejez (Barañano, 2021). Este apartado da cuenta de cómo son los tipos de hogar de las personas en la vejez en la ciudad de Barcelona.

En general, la composición de los hogares de los mayores en Barcelona muestra una independencia residencial hasta edades avanzadas que se manifiesta en una progresiva reducción de los hogares complejos (extensos, múltiples, sin núcleo); en un aumento de parejas sin hijos generadas a partir del incremento de los años vividos sin deceso de la pareja $-y$, por tanto, una mayor duración del "nido vacío"- y en un crecimiento de la de población que reside en hogares unipersonales hasta edades más avanzadas, mostrando una mayor durabilidad de la residencia en solitario al final de la vida (López-Villanueva y Pujadas, 2018). La independencia residencial de los mayores refleja un cambio en los comportamientos en la vejez, mostrando la preferencia de permanencia en el hogar y adaptando las estrategias familiares a ello (Zamora, Barrios, Lebrusan, Parant y Delgado, 2017).

Para obtener una dimensión evolutiva se han comparado los microdatos de la Encuesta Sociodemográfica de 2017 con los del Censo de 2001. La forma mayoritaria de residencia de los mayores de 65 años es el hogar de pareja sin hijos: en Barcelona (Figura 1), más de la mitad de los hombres $(54,59 \%)$ y más de un tercio de las mujeres $(36,51 \%)$ residen con su pareja o cónyuge aumentando significativamente las proporciones arrojadas por el Censo de 2001 que se situaban en $48,40 \%$ y $27,19 \%$, respectivamente. El crecimiento de las parejas sin hijos indica el aumento del número de años vividos al final del curso de vida del hogar a pesar de la emancipación domiciliaria tardía de los jóvenes en la ciudad -el 65,5\% entre 18 y 24 años y el $15 \%$ entre 25 y 34 vivía con alguno de sus progenitores en la ciudad de Barcelona según la Enquesta a la Joventut de Barcelona (2021)-.

Hombres y mujeres diversifican sus formas de residencia en la vejez y muestran pautas diferenciales. En
Población > 65 años 2001

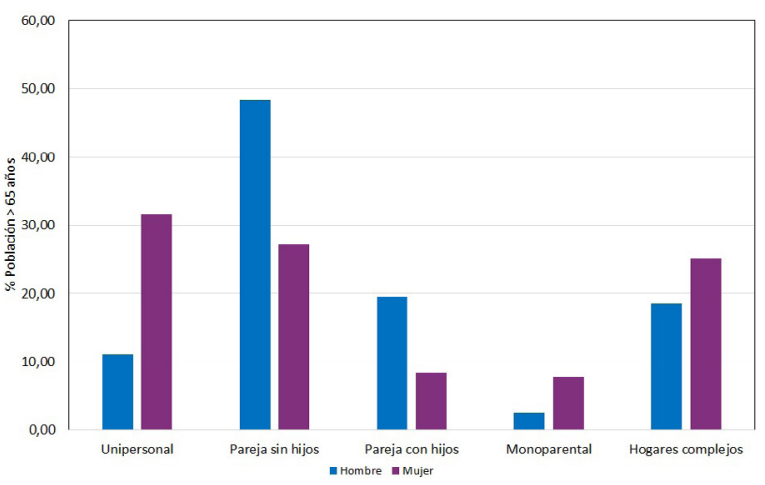

Población >65 años 2017

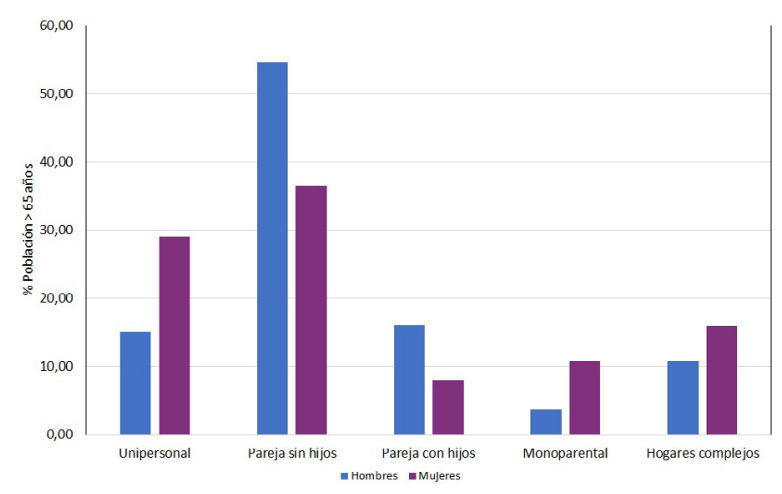

Fuente: Elaboración propia a partir de los microdatos del Censo de 2001 y de la Encuesta Sociodemográfica. Barcelona 2017 
el caso de los hombres, después del 54,59\% que vive con su pareja; el 15,97\% viven en hogares de parejas con hijos; seguidos del 15,09\% que reside en solitario y del $10,67 \%$ en hogares complejos; pocos son los varones que viven en hogares monoparentales (3,68\%).

Entre las mujeres, la segunda forma de residencia -después de la pareja- es la unipersonal; el 28,97\% de mujeres mayores de 65 años viven solas en Barcelona. Aquí se ha producido un cambio considerable de tendencia -que no solo se observa en la ciudad condal- y es que el hogar unipersonal ya no es la forma de residencia mayoritaria de las mujeres de edad; de hecho, el porcentaje de solitarias desciende levemente respecto al 31,61\% del año 2001. Este leve descenso de la población femenina que vive sola se ve compensado por el aumento de hogares de parejas sin hijos y a la vez contrarrestado por el incremento de hombres que residen en solitario.

La tercera forma de residencia entre las mujeres se encuentra en el hogar complejo $(15,91 \%)$ que reduce considerablemente sus efectivos en relación con 2001 cuando representaba el 25,06\%.

Le siguen los hogares monoparentales, el $10,68 \%$ de las mujeres en Barcelona viven solas con su(s) hijo(s), esta proporción crece respecto a 2001 cuando representaba el 7,73\% y triplica el porcentaje de los varones.

Finalmente, los hogares de parejas con hijos; en Barcelona el $7,93 \%$ de mujeres residen en núcleos simples completos, la mitad que los hombres, y reducen en ambos casos las proporciones respecto a 2001. El descenso es mucho más acusado entre los varones.
Estas cifras muestran la gran diferencia entre ambos sexos, residir en pareja y con los hijos es la segunda forma de residencia entre los hombres y la última entre las mujeres.

\section{Género, hogares y edades}

La evolución de la proporción de la población mayor por edades según tipo de hogar pone de manifiesto que la independencia residencial que emana de una nutrida representación de hogares de parejas sin hijos y unipersonales se va viendo mermada en favor de otros tipos de residencia a medida que la edad avanza.

Éste es el caso de los núcleos de parejas sin hijos que, a pesar de la elevada proporción (Figura 2) su valor va disminuyendo a medida que aumenta la edad, aunque hay que destacar la mayor duración hasta edades cada vez más avanzadas para reducirse a partir de los 80 años (Figura 3) -sobre todo entre las mujeres- cuando se produce el deceso del cónyuge.

Con la edad también aumenta la proporción de personas que viven solas (Figura 2). El $20 \%$ de los hombres de más de 80 años en la ciudad de Barcelona viven solos, en el caso de las mujeres es el $38,14 \%$, presentando un leve descenso respecto a 2001. A partir de los 85-90 años la residencia en solitario va perdiendo peso cuando no es posible sostener una independencia residencial, aunque persiste en las mujeres durante más tiempo (Figura 3).

Entre la población que reside en hogares de parejas con hijos la proporción va reduciéndose a medida que la población envejece. Cabe destacar un repunte en el
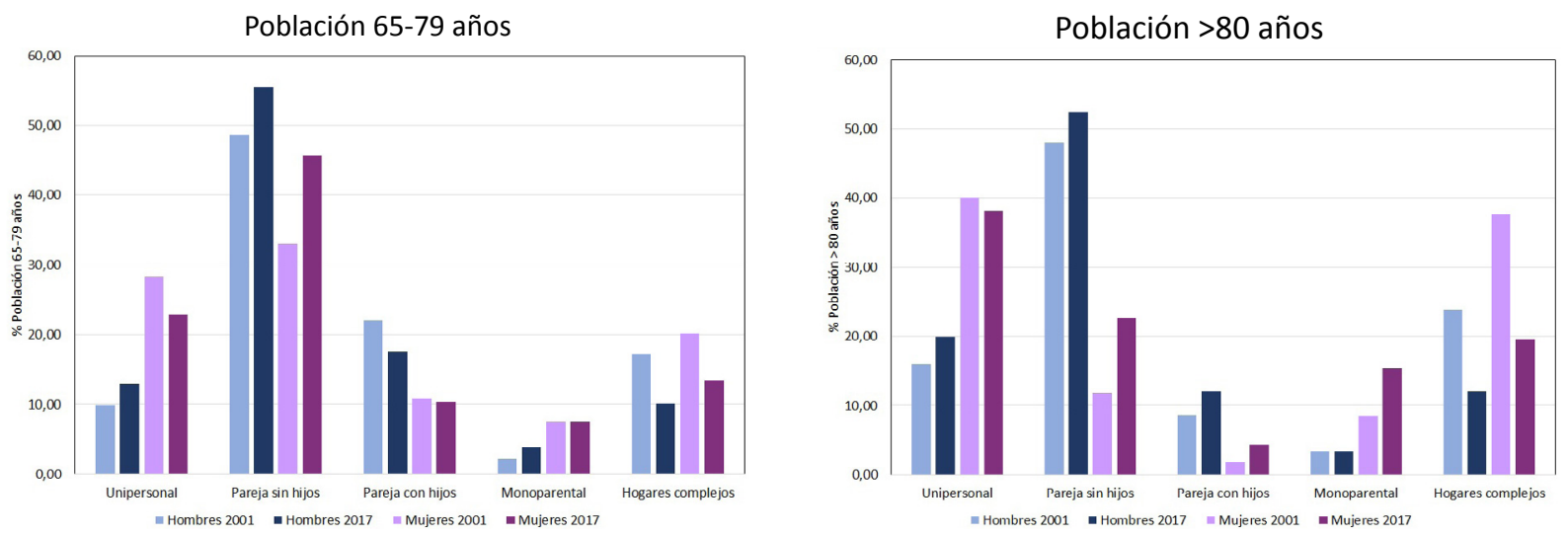
FIGURA 3

TIPOLOGÍA DE LOS HOGARES POR GRUPOS QUINQUENALES DE EDAD. HOMBRES Y MUJERES. BARCELONA 2017

Unipersonales

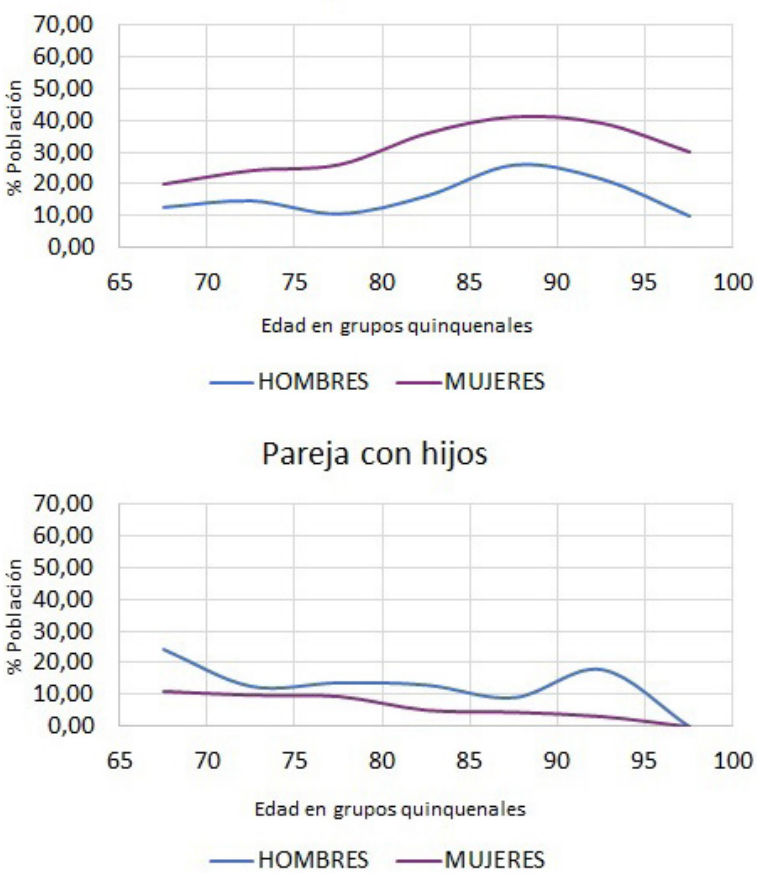

Pareja sin hijos

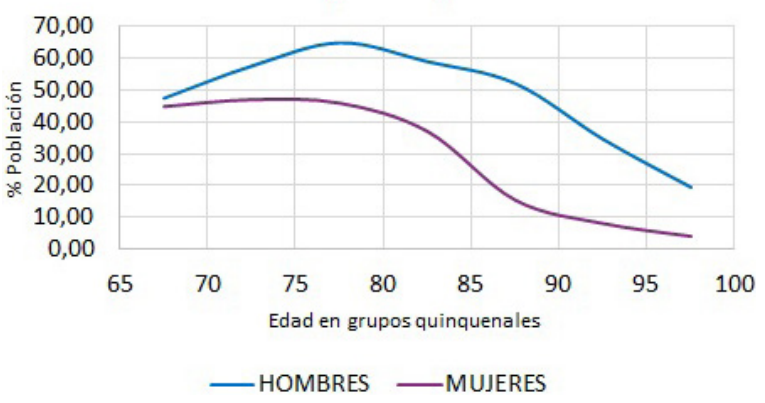

Monoparentales

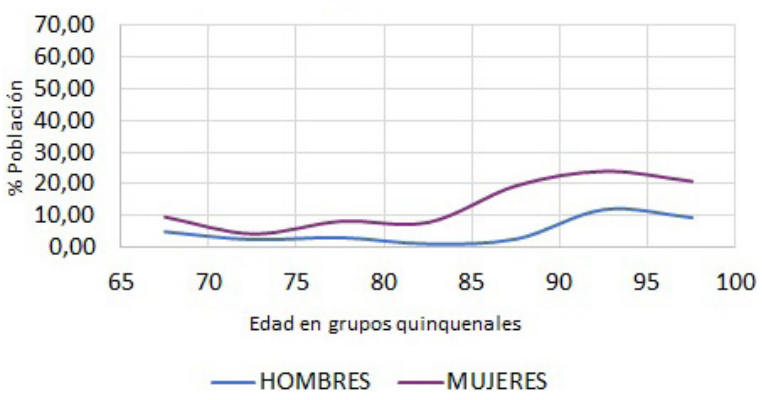

Hogares complejos

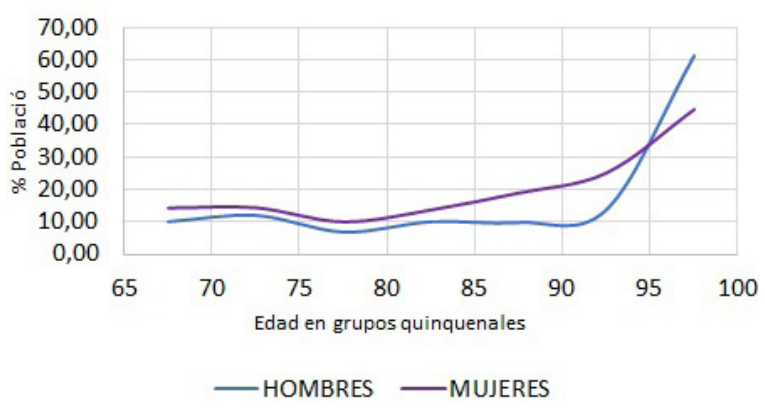

Fuente: Elaboración propia a partir de la Encuesta Sociodemográfica. Barcelona 2017

caso de los hombres a partir de los 85 años pudiendo responder a una estrategia de "fusión" o reagrupación.

Los residentes en hogares complejos van aumentando de manera sostenida con la edad en el caso de las mujeres a partir de los 80 años y de manera abrupta en los hombres, respondiendo a una estrategia de reagrupación cuando no es posible vivir de manera autónoma. Aunque su presencia es cada vez más reducida.

A pesar de que las formas de residencia en la vejez cada vez son más diversas y reflejan mayor presencia y duración de los mayores en hogares independientes, la edad y el género son elementos condicionantes que pueden intensificar la vulnerabilidad de los individuos en los hogares. La mayor presencia de hombres en hogares de parejas sin hijos y con hijos refleja el aumento de la esperanza de vida, pero también la diferencia de edad en la formación de las parejas. El hecho de vivir acompañado, sobre todo de la pareja no debe dejar pasar por alto el papel de cuidadoras de las mujeres. Vivir en pareja permite cuidados, atenciones y apoyos (Fernández-Carro, Gómez-Redondo y Cámara-Izquierdo, 2019) aunque también cabe tenerse en cuenta este papel, poco reconocido, en hombres tal y como se pone de manifiesto en el trabajo de Sundström, et al. (2018). 
FIGURA 4

COCIENTES DE LOCALIZACIÓN DE LA POBLACIÓN SEGÚN TIPO DE HOGAR. DISTRITOS BARCELONA. 2017

Unipersonales $>65$

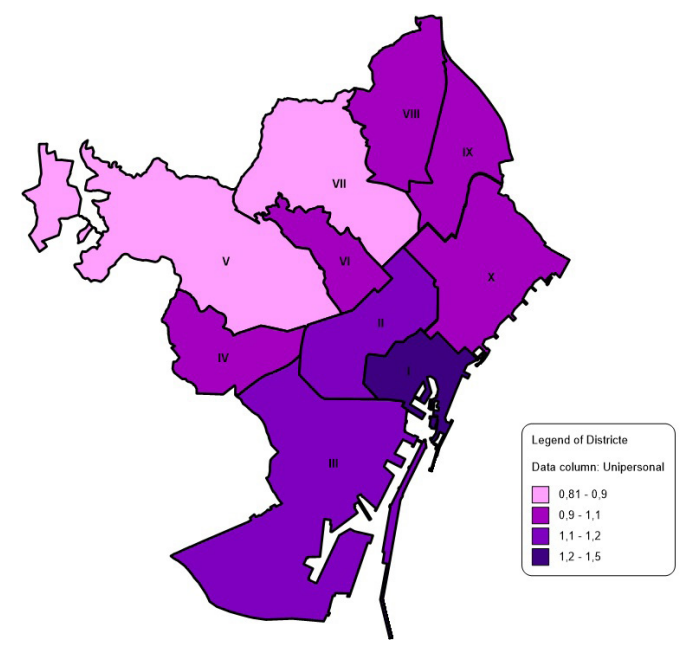

Parejas con hijos $>65$

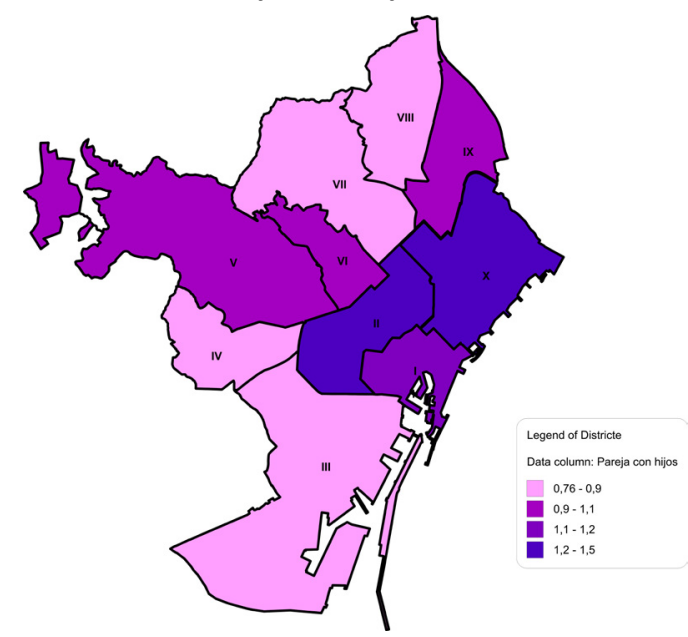

Parejas sin hijos $>65$

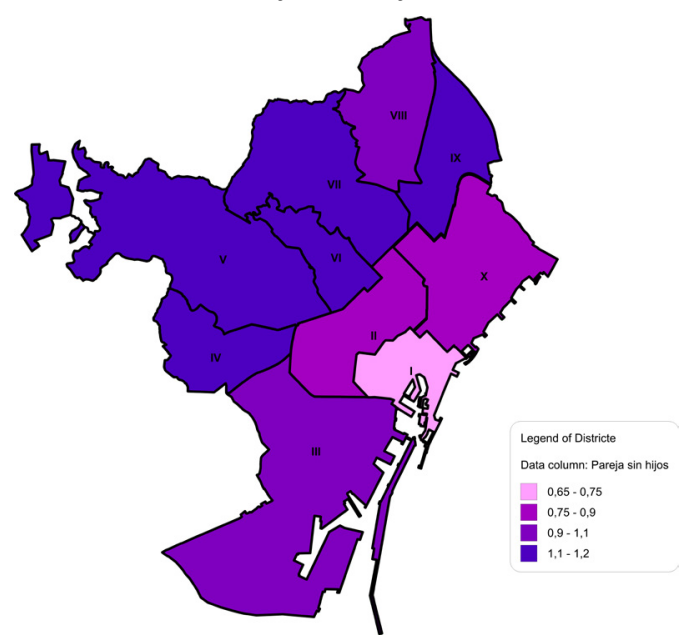

Monoparentales $>65$

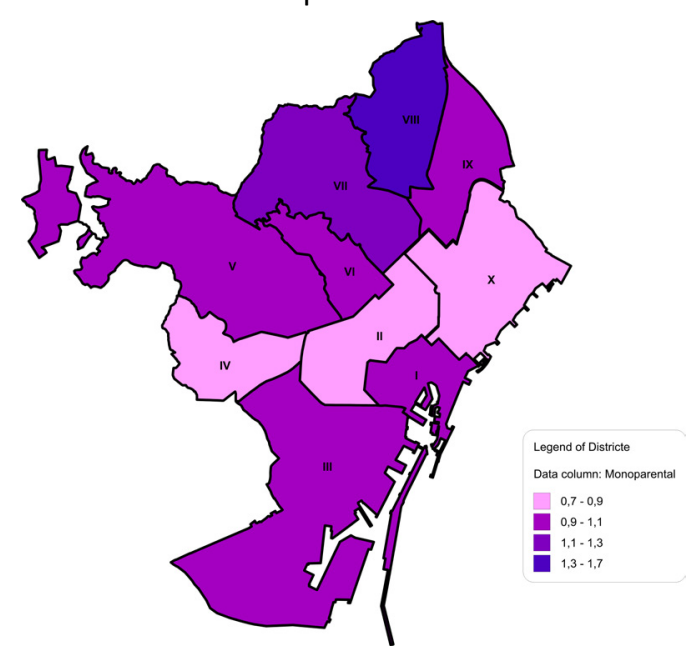

Complejos $>65$

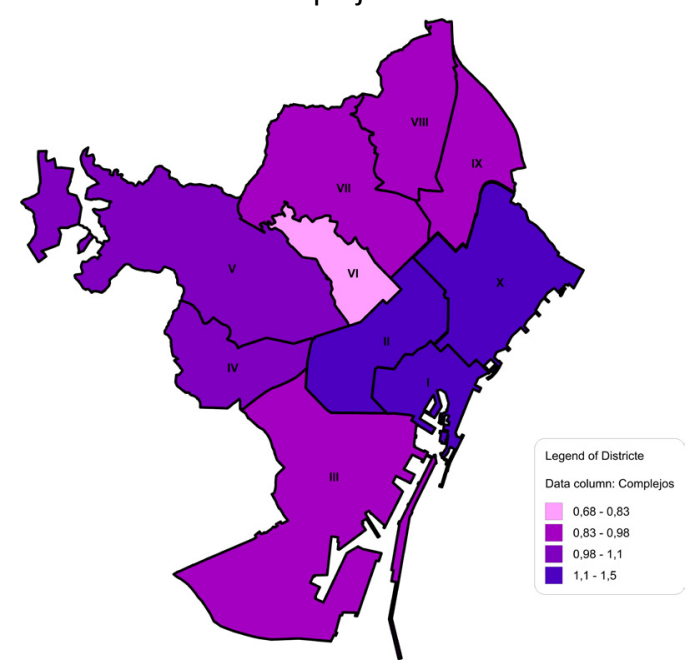

Fuente: Elaboración propia a partir de la Encuesta Sociodemográfica. Barcelona 2017 


\section{Mayores, hogares y territorio}

La composición de los hogares de la población mayor según los distritos de Barcelona muestra que la pauta dominante es el predominio de los hogares de parejas sin hijos y unipersonales en prácticamente todos los distritos, aunque con cierta variación en sus proporciones.

La mayor diversidad aparece entre el centro histórico -el distrito de Ciutat Vella- y el resto de la ciudad. Ciutat Vella -a pesar de la elevada proporción de población inmigrante de nacionalidad extranjera y de haber reducido su envejecimiento demográfico- continua con una alta concentración de hogares de población mayor que vive sola, tanto entre los 65-79 años (33,5\% de la población) como en los mayores de 80 $(49,7 \%$ de la población), y sin duda, es a la vez el distrito que acumula una mayor vulnerabilidad entre la población mayor. Esta alta proporción de solitarios se combina con la mínima presencia de hogares parejas sin hijos ( $29 \%$ contra el $44 \%$ del total de Barcelona).

En la figura 4 se representan los cocientes de localización de cada tipo de hogar en la vejez por distritos. Los índices superiores a 1 expresan una mayor presencia de una determinada tipología de hogar en comparación con el total de la ciudad, y contrariamente por debajo de 1 una menor concentración.

Los unipersonales destacan en Ciutat Vella $(1,49)$ y son también relevantes en los distritos de l'Eixample, Sants-Montjuic con una proporción del $25 \%$ y un coeficiente superior a 1,10. Siguen en importancia Gràcia y Nou Barris con una ligera sobrerrepresentación, y en cambio los índices de baja concentración, inferior a 1 , se dan en los distritos de Sant Martí, Sant Andreu, Horta, Les Corts i Sarrià. Estos últimos están formados por barrios con un alto crecimiento demográfico entre los años 60 y 80 del pasado siglo, con una población de parejas jóvenes con hijos que se instaló al inicio de su vida de adulta y que no ha completado su evolución hasta edades más avanzadas y ello puede explicar esta estructura con menor presencia de unipersonales de mayores

Los hogares complejos presentan una mayor regularidad al comparar los distritos de la ciudad. Las proporciones varían ligeramente entre $15 \%$ y $17 \%$ en los distritos de Ciutat Vella, Eixample, Les Corts y Sant Martí y entre $11 \%$ y el $14 \%$ Horta, Nou Barris, Sant Andreu y Sants. Únicamente destaca por una menor presencia de hogares complejos el distrito de Gràcia en que las transformaciones de la estructura familiar están relacionadas con llegada de nuevos residentes de población joven que han substituido a la población más anciana y han favorecido esta reducción.

Del mismo modo la monoparentalidad en edades avanzadas tiende a la homogeneidad entre los distritos de la ciudad. La viudedad -y más recientemente la divorcialidad- son situaciones que reflejan comportamientos generales y que no obedecen a pautas espaciales muy diferenciadas. No obstante, si se pueden destacar algunas situaciones de mayor concentración, tal como seria en los distritos de Nou Barris y Horta y una menor concentración en los distritos de clases medias y medias-altas como es el caso de l'Eixample y Les Corts.

\section{Matrimonio, soltería y viudedad}

El estado civil es un determinante del tipo de hogar en la vejez (Tabla 2), el 73\% de los hombres mayores de 65 años están casados frente al 47,47\% de las mujeres, entre las cuales el matrimonio comparte protagonismo con la viudedad (38,06\%). El matrimonio es el estado civil predominante entre los residentes en hogares nucleares de parejas con hijos y sin hijos, superando el $93 \%$ en todos los casos.

La viudez es el estado civil mayoritario de las personas que viven solas: el $42,46 \%$ de los hombres y el $70,55 \%$ de las mujeres, como también lo es de las personas que residen en hogares monoparentales (56,36\% en los hombres y $86,77 \%$ en las mujeres). La soltería y la ruptura de las uniones (separados y divorciados) alcanzan el 51,80\% entre los varones solitarios y el $38,13 \%$ entre los varones monoparentales.

La relación entre el estado civil y el bienestar ha sido explorada desde varias perspectivas tanto desde el punto de vista de la salud, sobre todo desde la salud mental, como desde la dimensión social. Vivir en pareja supone disponer de apoyos y cuidados informales que permite a las personas de edad prolongar la residencia el hogar. La pérdida de la pareja puede conllevar efectos adversos a nivel psicológico, e incrementar el aislamiento y la soledad. En el caso de las mujeres el deceso del cónyuge puede conllevar una disminución de los ingresos y, por tanto, un mayor riesgo de vulnerabilidad (Gumà y Fernández-Carro, 2021).

\section{Condiciones de vida en los hogares de los mayores}

\section{Características y condiciones de la vivienda}

La propiedad de la vivienda es dominante entre las personas mayores en Barcelona, más del 75,54\% 
TABLA 2

DISTRIBUCIÓN DEL ESTADO CIVIL SEGÚN TIPO DE HOGAR DE LAS PERSONAS MAYORES DE 65 AÑOS. BARCELONA 2017

\begin{tabular}{|c|c|c|c|c|c|c|}
\hline \multicolumn{7}{|c|}{ Hombres } \\
\hline & Solteros & Casados & Div.+Sep & Viudos & NC & Total \\
\hline Unipersonal & 26,82 & 5,01 & 24,98 & 42,46 & 0,73 & 100,00 \\
\hline Pareja sin hijos & 2,61 & 95,30 & 1,74 & 0,13 & 0,23 & 100,00 \\
\hline Pareja con hijos & 0,50 & 93,02 & 2,48 & 1,78 & 2,22 & 100,00 \\
\hline Monoparental & 14,93 & 5,51 & 23,20 & 56,36 & 0,00 & 100,00 \\
\hline Hogares complejos & 18,31 & 48,45 & 11,77 & 19,52 & 1,96 & 100,00 \\
\hline Total & 8,05 & 73,00 & 7,23 & 10,92 & 0,80 & 100,00 \\
\hline
\end{tabular}

\begin{tabular}{|l|c|c|c|c|c|c|}
\hline \multicolumn{7}{|c|}{ Mujeres } \\
\hline & Solteras & Casadas & Div.+Sep & Viudas & NC & Total \\
\hline Unipersonal & 14,82 & 2,43 & 10,76 & 70,55 & 1,44 & 100,00 \\
\hline Pareja sin hijos & 0,76 & 98,01 & 0,76 & 0,10 & 0,36 & 100,00 \\
\hline Pareja con hijos & 1,31 & 96,83 & 1,86 & 0,00 & 0,00 & 100,00 \\
\hline Monoparental & 2,20 & 0,66 & 9,70 & 86,77 & 0,67 & 100,00 \\
\hline Hogares complejos & 17,84 & 20,31 & 8,40 & 52,27 & 1,18 & 100,00 \\
\hline Total & 7,75 & 47,47 & 5,92 & 38,06 & 0,81 & 100,00 \\
\hline
\end{tabular}

Fuente: Elaboración propia a partir de la Encuesta Sociodemográfica. Barcelona 2017

TABLA 3

CARACTERÍSTICAS Y CONDICIONES VIVIENDA MAYORES 65 AÑOS. BARCELONA

\begin{tabular}{|l|c|c|c|c|c|c|c|}
\hline & $\begin{array}{c}\text { Resión } \\
\text { gratuita }\end{array}$ & $\begin{array}{c}\text { Alquiler precio } \\
\text { mercado }\end{array}$ & $\begin{array}{c}\text { Alquiler precio inferior } \\
\text { mercado otros motivos }\end{array}$ & $\begin{array}{c}\text { Alquiler precio inferior } \\
\text { mercado contrato } \\
\text { renta antigua }\end{array}$ & $\begin{array}{c}\text { En } \\
\text { propiedad }\end{array}$ & $\begin{array}{c}\text { Ocupado } \\
\text { Total }\end{array}$ \\
\hline Unipersonal & 4,68 & 9,20 & 3,51 & 13,12 & 69,48 & 0,00 & 100,00 \\
\hline Pareja sin hijos & 1,30 & 7,39 & 1,31 & 8,65 & 81,36 & 0,00 & 100,00 \\
\hline Pareja con hijos & 0,73 & 11,79 & 0,92 & 10,57 & 76,00 & 0,00 & 100,00 \\
\hline Monoparental & 0,72 & 8,54 & 3,90 & 18,42 & 68,41 & 0,00 & 100,00 \\
\hline Hogares complejos & 3,07 & 10,17 & 2,51 & 13,48 & 70,54 & 0,23 & 100,00 \\
\hline Total & 2,21 & 8,77 & 2,13 & 11,31 & 75,54 & 0,03 & 100,00 \\
\hline
\end{tabular}

\begin{tabular}{|c|c|c|c|c|c|c|c|}
\hline \multicolumn{8}{|c|}{ Año construcción de la vivienda } \\
\hline & $<1950$ & $1950-1970$ & 1971-1990 & 1991-2000 & $2001->2010$ & NS/NC & Total \\
\hline Unipersonal & 37,41 & 25,86 & 15,51 & 2,28 & 2,27 & 16,67 & 100,00 \\
\hline Pareja sin hijos & 31,95 & 31,19 & 21,17 & 4,73 & 2,64 & 8,32 & 100,00 \\
\hline Pareja con hijos & 28,83 & 25,44 & 24,78 & 5,87 & 4,77 & 10,31 & 100,00 \\
\hline Monoparental & 39,81 & 34,07 & 11,72 & 3,15 & 0,92 & 10,33 & 100,00 \\
\hline Hogares complejos & 35,60 & 23,99 & 14,50 & 5,80 & 2,65 & 17,47 & 100,00 \\
\hline Total & 33,96 & 28,55 & 18,64 & 4,32 & 2,67 & 11,87 & 100,00 \\
\hline
\end{tabular}

\begin{tabular}{|l|c|c|c|c|}
\hline \multicolumn{5}{|c|}{ Disponibilidad de calefacción } \\
\hline \\
\hline Unipersonal & No & Si & NS/NC & Total \\
\hline Pareja sin hijos & 40,94 & 56,89 & 2,17 & 100,00 \\
\hline Pareja con hijos & 25,77 & 73,50 & 0,73 & 100,00 \\
\hline Monoparental & 31,50 & 68,01 & 0,49 & 100,00 \\
\hline Hogares complejos & 34,97 & 54,12 & 0,91 & 100,00 \\
\hline Total & 35,55 & 63,09 & 1,36 & 100,00 \\
\hline
\end{tabular}

Fuente: Elaboración propia a partir de los microdatos de la Encuesta Sociodemográfica Barcelona. 2017 
TABLA 4

INGRESOS POR TIPO DE HOGAR. MAYORES 65 AÑOS. TRAMOS E INGRESOS MEDIOS EDAD

\begin{tabular}{|c|c|c|c|c|c|c|}
\hline \multicolumn{7}{|c|}{ Distribución tramos de ingresos mensuales por tipo de hogar } \\
\hline & $<1000$ & $1001-2000$ & 2001-3000 & $3001->5000$ & NS/NC & Total \\
\hline Unipersonal & 55,94 & 25,80 & 4,90 & 2,3 & 11,1 & 100,0 \\
\hline Pareja sin hijos & 10,00 & 47,33 & 17,70 & 7,9 & 17,1 & 100,0 \\
\hline Pareja con hijos & 5,60 & 35,13 & 19,93 & 16,5 & 22,8 & 100,0 \\
\hline Monoparental & 21,56 & 39,20 & 17,20 & 1,7 & 20,3 & 100,0 \\
\hline Hogares complejos & 8,85 & 32,99 & 19,47 & 9,8 & 28,9 & 100,0 \\
\hline Total & 20,80 & 38,41 & 15,21 & 7,4 & 18,2 & 100,0 \\
\hline
\end{tabular}

Fuente: Elaboración propia a partir de los microdatos de la Encuesta Sociodemográfica Barcelona. 2017

son propietarios (Tabla 3), esta proporción es menor si se compara con el total nacional en el Censo de 2011 que alcanza algo más del $86 \%$. Solo el $10,62 \%$ de los mayores propietarios tienen pago de hipoteca pendiente, proporción que se reduce al $1,85 \%$ en los mayores de 80.

El $22,21 \%$ vive en hogares de alquiler; el $13,44 \%$ paga a un precio inferior al del mercado, fundamentalmente por tratarse de contratos de renta antigua y desembolsan un precio inferior a 600 euros; estos alquileres son abonados por la población que reside mayoritariamente en hogares monoparentales, unipersonales y complejos.

El año de construcción (Tabla 3) refleja la antigüedad y las condiciones del parque de viviendas, así como el anclaje de los mayores en el domicilio. Un tercio de la población mayor $(33,96 \%)$ vive en edificios construidos antes de 1950 . El $17 \%$ reside en inmuebles anteriores al año 1920; solo el $7 \%$ reside en viviendas construidas posteriormente a 1990. Los mayores residentes en edificios más antiguos están más representados en hogares monoparentales, unipersonales y complejos. En relación con las condiciones, el $32,72 \%$-un tercio de la población mayor- no tiene calefacción en su domicilio (Tabla $3)$, porcentaje que se concentra, también en las personas que residen solas y en hogares monoparentales.

La propiedad de la vivienda es un elemento clave para explicar la permanencia en el domicilio en la vejez. Más allá de garantía de seguridad, independencia e identidad; en ocasiones, el hecho de quedarse en casa durante la vejez puede ser una consecuencia de la falta de recursos sociales y/o financieros que no permiten afrontar ninguna otra opción (Fernández-Carro y Evandrou, 2014) prisio- neros en su hogar (Pérez Díaz y Abellán, 2018). La vivienda previene o potencia la vulnerabilidad de las personas mayores en función de si es capaz de garantizar (Cortés 1995, citado en Lebrusan 2019) una estabilidad y un acceso asequible; una adaptación a las necesidades funcionales de sus ocupantes y una habitabilidad. La vivienda en propiedad es, también, un bien de transmisión patrimonial que contribuye a la seguridad financiera intergeneracional y sujeta a estrategias familiares complejas (Módenes y López Colás, 2014; Leal, 2010).

\section{Ingresos y condiciones socioeconómicas}

Los ingresos medios mensuales de las personas mayores por hogar muestran que los mayores ingresos se distribuyen entre la población que reside en las unidades residenciales con mayor número de miembros (Tabla 4): los hogares de parejas con hijos y los hogares complejos. Los ingresos medios más bajos se muestran en los hogares monoparentales. A medida que aumenta la edad los ingresos mensuales medios disminuyen excepto en los hogares complejos. Los ingresos medios por hogar por debajo del umbral de pobreza ${ }^{1}$ se sitúan en los hogares unipersonales de mayores de 80 años.

Es evidente que los ingresos del hogar van en función del número de miembros. El hecho de residir sin convivientes disminuye la renta del hogar. La reducción de ingresos después de la jubilación puede situar la población mayor en situación de vulnerabilidad por no poder hacer frente a las nuevas necesidades de adaptación de la vivienda o simplemente para poder hacer frente a los gastos cotidianos.

\footnotetext{
111.520 euros anuales por hogar de un adulto en Barcelo-
} na según la encuesta 


\section{Estado de salud y necesidad de ayuda}

La percepción del estado de salud de los mayores es buena, el $42 \%$ afirma encontrarse bien de salud. Si se añade la proporción de los que afirman encontrarse muy bien suman el $52,44 \%$ y se concentran en los hogares de parejas sin hijos y con hijos (Tabla 5). Ello es un buen indicador de su independencia residencial. El $14,67 \%$ declaran tener un estado malo o muy malo y presentan mayores valores en la población que reside en hogares monoparentales y parejas con hijos. El buen estado de salud se corresponde con la afirmación de no necesitar ayuda o compañía para realizar actividades básicas, el 71,85\% no necesitan ayuda frente al 23,53\% que expresan precisar compañía o ayuda y esto sucede más en las personas que residen en hogares monoparentales y complejos.

A medida que avanza la edad, se acentúan las afecciones de salud; la mortalidad empieza a afectar al entorno personal más cercano y se tiende a contraer la movilidad, las redes y las relaciones sociales (GarcíaBallesteros y Jiménez Blasco, 2016) pudiendo ocasionarse una situación de fragilidad que se agrava en las grandes ciudades en las cuales exista una más débil red social de intercambio y una menor proximidad con los familiares o allegados. El estado de salud y la necesidad de ayuda para realizar actividades cotidianas puede verse agravado por el estado y la condición de la vivienda de un parque antiguo.

\section{HOGARES Y VULNERABILIDAD}

Con la finalidad de mostrar las correlaciones de valores entre las formas de hogar y las diferentes dimensiones de la vulnerabilidad, se han realizado tablas de contingencia Ji cuadrado entre estas variables y la tasa de riesgo de pobreza estimada de la encuesta -que, como se ha mencionado, fija el umbral en $11.520,0$ $€$ netos anuales por hogares de un adulto- así como entre estas variables y los tipos de hogar.

El índice $\mathrm{V}$ de Cramer permite determinar la intensidad de asociación entre diferentes aspectos de la vulnerabilidad con uno de sus elementos centrales: el riesgo de pobreza; también seleccionar qué tablas de contingencia se deben estudiar con detalle; y cuáles son las formas de convivencia más vinculadas al proceso de vulnerabilidad.

Los valores de Ji cuadrado corregido por V de Cramer destacan la importancia de las formas de hogar en las diferentes dimensiones del proceso de vulnerabilidad de las personas mayores (Tabla 7), especialmente por su alta correlación con el riesgo de pobreza (Tabla 6). Los diferentes tipos de hogar, es decir, la diferente capacidad para generar modelos de convivencia y ayuda es la variable que tiene una mayor correlación con el riesgo de pobreza $(0,291)$. Este nivel, pasa por delante de las variables asociadas con más frecuencia a la vulnerabilidad por la literatura especializada: el barrio

TABLA 5

PERCEPCIÓN ESTADO DE SALUD, LIMITACIÓN PARA REALIZAR ACTIVIDADES Y NECESIDAD DE AYUDA DE LOS MAYORES DE 65 AÑOS POR TIPO DE HOGAR. BARCELONA 2017

\begin{tabular}{|l|c|c|c|c|c|c|c|}
\hline \multicolumn{7}{|c|}{ Percepción estado de salud } \\
\hline & Muy malo & Malo & Regular & Bueno & Muy bueno & Nc & Total \\
\hline Unipersonal & 3,01 & 9,80 & 36,97 & 40,71 & 9,51 & 0,00 & 100,00 \\
\hline Pareja sin hijos & 3,01 & 9,97 & 29,81 & 46,79 & 10,11 & 0,31 & 100,00 \\
\hline Pareja con hijos & 4,09 & 11,65 & 30,56 & 44,17 & 9,17 & 0,36 & 100,00 \\
\hline Monoparental & 9,12 & 17,62 & 29,88 & 33,67 & 9,70 & 0,00 & 100,00 \\
\hline Hogares complejos & 7,51 & 8,06 & 38,37 & 31,26 & 14,79 & 0,00 & 100,00 \\
\hline Total & 4,22 & 10,45 & 32,72 & 41,97 & 10,47 & 0,18 & 100,00 \\
\hline
\end{tabular}

\begin{tabular}{|l|c|c|c|c|c|c|c|c|c|c|}
\hline \multicolumn{4}{|c|}{ Limitación para realizar actividades habituales } & \multicolumn{3}{c|}{ Precisa ayuda o compañía para realizar actividades cotidianas } \\
\hline & No & A veces & Si & NC & Total & No & Si & A veces & NC & Total \\
\hline Unipersonal & 58,80 & 31,32 & 6,37 & 3,51 & 100,00 & 68,11 & 14,57 & 12,75 & 4,57 & 100,00 \\
\hline Pareja sin hijos & 68,28 & 21,47 & 7,12 & 3,14 & 100,00 & 79,84 & 8,72 & 7,21 & 4,24 & 100,00 \\
\hline Pareja con hijos & 65,52 & 24,68 & 9,44 & 0,36 & 100,00 & 76,51 & 10,38 & 11,11 & 1,99 & 100,00 \\
\hline Monoparental & 46,78 & 30,32 & 19,71 & 3,19 & 100,00 & 53,26 & 15,66 & 26,71 & 4,37 & 100,00 \\
\hline Hogares complejos & 52,60 & 27,75 & 12,60 & 7,06 & 100,00 & 58,82 & 13,05 & 19,88 & 8,25 & 100,00 \\
\hline Total & 61,99 & 25,64 & 8,93 & 3,45 & 100,00 & 71,85 & 11,38 & 12,15 & 4,62 & 100,00 \\
\hline
\end{tabular}

Fuente: Elaboración propia a partir de los microdatos de la Encuesta Sociodemográfica Barcelona. 2017 
TABLA 6

INTENSIDAD DE ASOCIACIÓN ENTRE EL RIESGO DE POBREZA Y DIFERENTES INDICADORES DE LA VULNERABILIDAD [V DE CRAMER]

\begin{tabular}{|c|c|c|}
\hline \multicolumn{3}{|c|}{ Asociación con la tasa de riesgo de pobreza [V de Cramer] } \\
\hline & $\begin{array}{l}\text { Población de } \\
65 \text { años y más }\end{array}$ & $\begin{array}{l}\text { Población } \\
\text { general }\end{array}$ \\
\hline Estructura del hogar & 0,291 & 0,230 \\
\hline Hogar unipersonal & 0,249 & 0,077 \\
\hline Nivel de estudios & 0,254 & 0,229 \\
\hline Sin estudios / leer escrib. & 0,179 & 0,083 \\
\hline Limitación (sí, a veces) & 0,119 & 0,090 \\
\hline Salud (mala y muy mala) & 0,128 & 0,095 \\
\hline Necesita ayuda (actividades básicas) & 0,154 & 0,104 \\
\hline Paga por su vivienda (alquiler / hipoteca) & 0,123 & 0,164 \\
\hline Vivienda equipada con calefacción & 0,189 & 0,222 \\
\hline $\begin{array}{l}\text { Antigüedad de la vivienda (anterior } \\
\text { 1975) }\end{array}$ & 0,104 & 0,047 \\
\hline Edad (80 años y más) & 0,150 & 0,069 \\
\hline Sexo (mujer) & 0,119 & 0,034 \\
\hline Barrio de residencia & 0,269 & 0,302 \\
\hline Aloctonía (nacionalidad española / extr.) & 0,093 & 0,151 \\
\hline Aloctonía (residencia anterior -países-) & 0,205 & 0,321 \\
\hline $\begin{array}{l}\text { Aloctonía (misma com, resto de Esp, } \\
\text { extr.) }\end{array}$ & 0,079 & 0,106 \\
\hline
\end{tabular}

a. Significación estadística al $99 \%$ de confianza para todos los valores Fuente: Elaboración propia a partir de los microdatos de la Encuesta Sociodemográfica Barcelona. 2017

de residencia $(0,269)$, que muestra la existencia de una distribución urbana segregada en función de los recursos y que concentra la población vulnerable en determinadas zonas; el nivel de estudios $(0,254)$, una de las variables que mejor aproxima la posición social condensando las desigualdades de capital cultural por un lado, y económico -a cuenta de un mercado de trabajo dual y segmentado-; o la aloctonía $(0,205)$. En este punto, se han incluido tres indicadores de aloctonía: uno que distingue entre la nacionalidad española y la nacionalidad extranjera para detectar efectos derivados del acceso a la nacionalidad; otro que distingue entre residencia anterior en municipio de Cataluña, residencia anterior en municipios de otras comunidades autónomas y residencia anterior en municipios de países extranjeros, para detectar efectos derivados de la pérdida de capital social y de capital simbólico de pertenencia por haber efectuado un cambio residencial de comunidad autónoma; y, final- mente, un indicador que distingue específicamente en función del país de residencia anterior. Este último indicador de aloctonía es el que correlaciona más intensamente con el riesgo de pobreza $(0,205)$. Así, más que el acceso a los derechos derivados de la nacionalidad, o la importancia de las redes sociales cultivadas durante años, la dimensión de la aloctonía que más influye en el proceso de vulnerabilidad es la migración internacional por razones económicas, especialmente si esta se produce desde países con un menor desarrollo -valorados en términos de PIB-.

La capacidad para establecer formas de convivencia y solidaridad, que podríamos denominar "capital social familiar", protege de la vulnerabilidad a todas las edades, pero adquiere mayor importancia entre la población de más de 65 años. Para el conjunto de la población, la aloctonía por país $(0,321)$ y el barrio de residencia $(0,302)$ pasan a ser las variables más correlacionadas con el riesgo de pobreza y las formas de hogar descienden a la tercera posición $(0,23)$, junto al nivel de estudios $(0,229)^{2}$.

Las diferentes categorías de tipo de hogar presentan una relación muy diferente frente a la vulnerabilidad en función de la edad. Por ejemplo, los hogares unipersonales pasan de correlacionar $(0,249)$ para los mayores de 64 años, a una correlación del 0,077 para el conjunto de la población. Mientras para una persona de 30 años la capacidad para vivir en su propio hogar puede ser un indicador de independencia, mayores rentas y acceso al empleo; para una persona de 70 años puede indicar aislamiento y pérdida del capital social familiar. Aunque con menos intensidad, se observa que lo contrario ocurre con los hogares complejos y sin núcleo: son la categoría más asociada al riesgo de pobreza entre la población general, pero en posiciones intermedias para la población de más de 64 años. Este cambio en la importancia de cara al proceso de vulnerabilidad en función de la edad, también aparece en otras variables: todas las variables sociodemográficas (edad y género), así como las relativas al estado de salud, la necesidad de cuidados y la dependencia potencian su relación con la vulnerabilidad para el grupo mayor de 64 años. Al contrario, las variables relacionadas con la aloctonía y el barrio de residencia pierden parte de su asociación con la vulnerabilidad para el grupo de per-

2 Este diferencial por edades en la correlación entre formas de convivencia y vulnerabilidad resulta aún más pronunciado si en vez de la variable riesgo de pobreza se emplea la de privación material severa (el cruce con otros indicadores económicos de vulnerabilidad lleva a conclusiones similares, por lo que no se han incluido). 
sonas mayores. Es decir, entre la población mayor de 64 años, las variables sociodemográficas y de salud adquieren una mayor importancia relativa en el proceso de vulnerabilidad mientras que, las variables relacionadas con la posición en la estructura social como el barrio o la aloctonía tienen un efecto importante, pero relativamente menor.

Entre las variables susceptibles de formar parte de los procesos de vulnerabilidad (Tabla 7), las que presentan una mayor asociación con la forma de hogar son la tasa de riesgo de pobreza $(0,291$ y muy relacionada con la capacidad de hacer frente a gastos imprevistos), la edad $(2,31)$, el género (aproximado por el sexo con asociación de 2,70 ) y el barrio de residencia $(0,226)$.

Cuando se analizan estos cruces en detalle se puede observar qué formas de convivencia presentan mayores pesos de la población con características asociadas a la vulnerabilidad. En primer lugar, la especialización de las formas de hogar en función de la edad es mayor para el total de la población que para la población más mayor. Cuando se incluye el total de la población, los grupos de menos edad se concentran en las formas de parejas con hijos y la población de más de 650 de más de 80 en hogares unipersonales y monoparentales, probablemente debido a la fuerte vinculación que tiene la crianza y la disolución de la pareja por viudedad con el ciclo de vida. La especialización por género de las formas de hogar entre las personas mayores responde al mismo fenómeno, es muy alta en la población mayor por la asociación de la viudedad con las edades avanzadas. En todo caso no añaden información sobre el proceso de vulnerabilidad, más allá de la interseccionalidad que se produce entre feminización, viudedad y formas de convivencia con un mayor aislamiento de las personas mayores.

La mayor segregación territorial de las formas de hogar entre las personas mayores (de una asociación de 0,157 para la población general, a una de 0,226 para mayores de 65 años) da cuenta de dos dinámicas: por un lado, el efecto generacional en la construcción, población y relevo de ciertos barrios y, por otro, de la segregación asociada a la pobreza de las formas de hogares más vulnerables entre personas mayores (unipersonales, monoparentales y complejos).

Finalmente, el riesgo de pobreza en función del tipo de hogar (Tabla 8) nos permite detectar qué formas de convivencia se asocian más a la vulnerabilidad y en qué medida se intensifica esta asociación entre las personas mayores. Para cualquier edad, la convivencia en pareja es la que presenta un menor porcentaje de personas vulnerables $(9,4 \%$ entre los mayores de
TABLA 7

INTENSIDAD DE ASOCIACIÓN ENTRE EL RIESGO DE POBREZA Y DIFERENTES INDICADORES DE LA VULNERABILIDAD [V DE CRAMER]

\begin{tabular}{|c|c|c|}
\hline \multicolumn{3}{|c|}{ Asociación con la tasa de riesgo de pobreza [V de Cramer] } \\
\hline & $\begin{array}{l}\text { Población de } \\
65 \text { años y más }\end{array}$ & $\begin{array}{l}\text { Población } \\
\text { general }\end{array}$ \\
\hline Tasa de riesgo de pobreza & 0,291 & 0,219 \\
\hline No pueden permitirse vacaciones & 0,114 & 0,147 \\
\hline No pueden permitirse proteinas animales & 0,080 & 0,102 \\
\hline No pueden permitirse gastos imprevistos & 0,175 & 0,209 \\
\hline $\begin{array}{l}\text { No pueden permitirse encender la } \\
\text { calefacción }\end{array}$ & 0,047 & 0,155 \\
\hline Nivel de estudios & 0,115 & 0,144 \\
\hline Sin estudios / leer escrib. & 0,198 & 0,202 \\
\hline Limitación (sí, a veces) & 0,143 & 0,165 \\
\hline Salud (mala y muy mala) & 0,104 & 0,102 \\
\hline Necesita ayuda (actividades básicas) & 0,133 & 0,089 \\
\hline
\end{tabular}

\begin{tabular}{|l|l|l|}
\hline Paga por su vivienda (alquiler / hipoteca) & 0,112 & 0,170 \\
\hline Vivienda equipada con calefacción & 0,155 & 0,188 \\
\hline Antigüedad de la vivienda (anterior 1975) & 0,096 & 0,157 \\
\hline
\end{tabular}

\begin{tabular}{|l|l|l|}
\hline Edad (80 años y más) & 0,231 & 0,286 \\
\hline Sexo (mujer) & 0,270 & 0,093 \\
\hline
\end{tabular}

\begin{tabular}{|l|l|l|}
\hline Barrio de residencia & 0,226 & 0,157 \\
\hline
\end{tabular}

\begin{tabular}{|l|l|l|}
\hline Aloctonía (nacionalidad española / extr.) & 0,076 & 0,087 \\
\hline Aloctonía (residencia anterior -países-) & 0,187 & 0,161 \\
\hline Aloctonía (misma com, resto de Esp, extr.) & 0,073 & 0,145 \\
\hline
\end{tabular}

a. Significatividad estadística al $99 \%$ de confianza para todos los valores Fuente: Elaboración propia a partir de los microdatos de la Encuesta Sociodemográfica Barcelona. 2017

64 años y 10,2\% entre los menores de 65). De aquí no puede inferirse causalidad. La disociación entre la convivencia en pareja y la vulnerabilidad podría explicarse por la capacidad de las parejas de aumentar las posibilidades de conseguir recursos y dividir los gastos. Pero también es posible que las situaciones de pobreza y vulnerabilidad dificulten la estabilidad de los proyectos de pareja. En el caso de las parejas con hijos, la explicación parece más clara: aumenta un $30 \%$ el riesgo de pobreza del hogar, pero se mantiene entre los niveles más bajos de la distribución. En el caso de hijos pequeños, los gastos asociados a la crianza aumentan el riesgo de pobreza (hasta el 14,6\%). En el caso de hijos en edad de trabajar y padres mayores de 65 años, es posible que su convivencia indique la falta de recursos suficientes para mantener dos hogares diferenciados (proporción del 15,2\%). 
TABLA 8

PORCENTAJE DE POBLACIÓN EN RIESGO DE POBREZA POR GRUPO DE EDAD Y TIPO DE HOGAR

\begin{tabular}{|l|c|c|}
\hline \multirow{2}{*}{\multicolumn{1}{|c|}{ Tipos de hogar }} & \multicolumn{2}{c|}{ Riesgo de pobreza } \\
\cline { 2 - 3 } & $\mathbf{6 5}$ años y más & Menos de 65 años \\
\hline H. Unipersonal & $38,3 \%$ & $21,0 \%$ \\
\hline H. Pareja sin hijos & $9,4 \%$ & $10,5 \%$ \\
\hline H. Pareja con hijos & $15,2 \%$ & $14,6 \%$ \\
\hline H. Monoparental & $25,2 \%$ & $28,3 \%$ \\
\hline H. Complejos & $25,3 \%$ & $34,8 \%$ \\
\hline
\end{tabular}

Fuente: Elaboración propia a partir de los microdatos de la Encuesta Sociodemográfica Barcelona. 2017

Así, los hogares que no están construidos en base a una relación de pareja tienen un comportamiento muy diferente en función de la edad. Como decíamos, los hogares unipersonales son la forma de hogar sin pareja más vulnerable entre las personas mayores $(38,3 \%$ en riesgo de pobreza), pero la menos vulnerable entre los menores de 65 (21\%). Para las personas mayores, tanto la monoparentalidad como cualquier otra forma de composición de la convivencia presentan cifras más bajas de vulnerabilidad (tanto en riesgo de pobreza como en privación material severa) que vivir en hogares unipersonales, del $25,2 \%$ y $25,3 \%$, respectivamente. Entre la población menor de 65 años, la mayor vulnerabilidad se produce en los hogares complejos $(34,8 \%)$. Es posible que las formas de convivencia diferentes de la familia nuclear sean, para una parte, de la población una opción forzada por las situaciones de carestía, o la imposibilidad de acceder a una vivienda que una preferencia decidida en libertad.

\section{CONCLUSIONES}

Los hogares de los mayores han protagonizado en las últimas décadas grandes transformaciones: han aumentado su presencia y han diversificado su estructura y su composición mostrando una creciente independencia residencial a edades avanzadas que se muestra en la reducción del tamaño del hogar, en un aumento de personas de edad que comparten el hogar con su pareja o cónyuge o de los que residen en solitario, así como una disminución de la proporción de personas que viven en hogares intergeneracionales de mayor complejidad. La permanencia en el hogar hasta edades avanzadas que representaría la independencia residencial se transforma en un arma de doble filo: por un lado, los beneficios de la vida independiente; por otro, las dificultades para afrontar diferentes niveles de dependencia y que posiciona en una situación de vulnerabilidad.
La vejez implica un cambio en la vinculación con el entorno. Si bien es cierto que existe una gran diversidad de situaciones en un grupo de edad tan dilatado, que normativamente comenzaría a partir de los 65 años de la mano de la jubilación, conlleva importantes modificaciones en diferentes dimensiones de la vida: espacios, tiempos y distancias recorridos; actividades desarrolladas; transformaciones de las rutinas y cambios en las relaciones sociales. A medida que avanza la edad, se acentúan las afecciones de salud; la mortalidad empieza a afectar al entorno personal más cercano y se tiende a contraer la movilidad, las redes y las relaciones sociales.

El objetivo del trabajo ha consistido en estudiar la relación existente entre la tipología de hogares de los mayores y su papel en la incidencia de vulnerabilidad en la ciudad de Barcelona.

Los resultados del análisis ponen de manifiesto la importancia de la tipología del hogar en los procesos de vulnerabilidad de los mayores en la ciudad de Barcelona. Las formas de convivencia en las personas de edad avanzada muestran una mayor asociación con la tasa del riesgo de pobreza que otro tipo de variables vinculadas a la vulnerabilidad. Los hogares de mayores con otros convivientes están más protegidos y tienen mayor capacidad para hacer frente a diferentes situaciones de vulnerabilidad. Los datos dan cuenta de un sistema familiarista donde la convivencia con la pareja tiene un papel muy relacionado con la prevención de la vulnerabilidad. A diferencia del resto de la población, la convivencia con los hijos ya mayores, con familiares de segundo y tercer grado o cualquier otro tipo de composición de hogar es preferible a la residencia en solitario en las edades avanzadas. La intensidad de la asociación entre tipo de hogar y vulnerabilidad muestra valores más elevados en las variables relacionadas con la tasa de riesgo de pobreza, sobre todo en la capacidad para hacer frente a gastos imprevistos. Destaca una alta asociación entre feminización, viudedad y hogar unipersonal. La asociación entre el tipo de hogar y el barrio es alta y ello informa de la especialización residencial que conllevaron las dinámicas poblamiento de determinados barrios de la ciudad, unido ahora a un proceso de envejecimiento.

Los hogares de mayores unipersonales, monoparentales y complejos son los que presentan una mayor vulnerabilidad.

Este trabajo pretende contribuir a la comprensión de la evolución de los tipos de hogar en la vejez y aportar elementos de reflexión a la residencia independiente de los mayores en sus propios hogares y 
barrios en los cuales existe un apego y arraigo. Las ciudades deben adaptarse a las necesidades de poblaciones envejecidas con necesidades crecientes tanto en lo que se refiere a la adecuación de los hogares, a los soportes y apoyos y a las infraestructuras.

\section{FUENTES DE FINANCIACIÓN}

Este trabajo se ha desarrollado en el marco del proyecto I+D+i Nuevas movilidades y reconfiguración socio residencial en la poscrisis: Consecuencias socioeconómicas y demográficas en las áreas urbanas españolas. Ref. RTI2018-095667-B-I00 financiado por el Ministerio de Ciencia, Innovación y Universidades

\section{REFERENCIAS}

Ajuntament de Barcelona (2021). Enquesta de la Joventut de Barcelona. Informe de resultats. Ajuntament de Barcelona.

Barañano, M. (2021). Los hogares como espacios de arraigo y sus transformaciones en un contexto global. Encrucijadas. Revista Crítica de Ciencias Sociales, 21 (1).

Bayona-i-Carraso, J. y Pujadas, I. (2014). Movilidad residencial y redistribución de la población metropolitana: los casos de Madrid y Barcelona. Eure, 40 (119), 261-287, http://dx.doi.org/10.4067/ S0250-71612014000100012

Cairney, J. y Boyle, M. H. (2004). Home ownership, mortgages and psychological distress. Housing Studies, 19(2), 161-174, https://doi. org/10.1080/0267303032000168577

Castel, R. (1991). La dinámica de los procesos de marginación: de la vulnerabilidad a la exclusión en Acevedo, M.; Volnovich, J.C. El espacio institucional (pp. 37-54). Buenos Aires, Argentina: Lugar Editorial.

Choi, N. G. (1996). The never-married and divorced elderly: Comparison of economic and health status, social support, and living arrangement. Journal of Gerontological Social Work, 26 (1-2), 3-25, https://doi.org/10.1300/J083V26N01_02

Cortés, L. (1995). La cuestión residencial. Bases para una sociología del habitar. Madrid: Editorial Fundamentos.

Costa-Font, J., Elvira, D. y Mascarilla-Miró, O. (2009). Ageing in place? Exploring elderly people's housing preferences in Spain. Urban studies, 46 (2), 295316, https://doi.org/10.1177/0042098008099356
Cutter, S. L., Boruff, B. J. y Shirley, W. L. (2003). Social vulnerability to environmental hazards. Social science quarterly, 84(2), 242-261, https://doi. org/10.1111/1540-6237.8402002

De Jong Gierveld, J. (2004). Remarriage, unmarried cohabitation, living apart together: Partner relationships following bereavement or divorce. Journal of marriage and family, 66 (1), 236-243, https:// doi.org/10.1111/j.0022-2445.2004.00015.x

Deci, E. L. y Ryan, R. M. (2008). Facilitating optimal motivation and psychological well-being across life's domains. Canadian Psychology/Psychologie Canadienne, 49, 14-23, https://doi.org/10.1037/07085591.49.1.14

De Cos, O. y Usobiaga, E. (2019). Retos metodológicos para estudiar la vulnerabilidad demográfica y residencial a nivel intraurbano ante los cambios en las fuentes estadísticas habituales. Sripta Nova, XXIII (606), https://doi.org/10.1344/sn2019.23.21614

Departamento de Asuntos Económicos y Sociales. Naciones Unidas (2003). Informe sobre la situación social del mundo 2003. Vulnerabilidad social: Fuentes y desafíos. Nueva York: United Nations Publications.

Diputació de Barcelona (2019). Índex de vulnerabilitat social dels municipis de la demarcació de Barcelona. IVSO. Àrea de Recursos Humans, Hisenda i Serveis Interns. Direcció de Serveis de Planificació Económica. Barcelona, España: Diputació de Barcelona.

Doblas, J. L. (2018). Formas de convivencia de las personas mayores. REIS. Revista Española de Investigaciones Sociológicas, 161, 23-40, https://doi. org/10.5477/cis/reis.161.23

Domingo, A. y Bayona-i-Carrasco, J. (2010). Los hogares de la población de nacionalidad extranjera en España en el año 2001. Papers: Revista de Sociologia, 95 (3), 0731-754, http://dx.doi.org/10.5565/ rev/papers/v95n3.65

Domingo, A., Galeano, J. y Bayona-i-Carrasco, J. (2021). La migració estrangera a Barcelona: de la crisi financera del 2008 a la pandèmia del 2020. Barcelona Societat, 28, 26-40.

Esteve, A., Devolder, D. y Domingo, A. (2016). La infecundidad en España: tic-tac, tic-tac, tic-tac!!!, Perspectives Demogràfiques, 1, 1-4.

Esteve, A. y Treviño, R. (2019). Los grandes porqués de la (in) fecundidad en España. Perspectives Demogràfiques, 15, 1-4. 
Fernández-Carro, C. y Evandrou, M. (2014). Staying put: Factors associated with ageing in one's lifetime home. Insights from the European context. Research on Ageing and Social Policy, 2 (1), 28-56, http://dx.doi.org/10.4471/rasp.2014.02

Fernández-Carro, C., Gómez-Redondo, R. y CámaraIzquierdo, N. (2019). The availability of carers for older disabled people in Spain: demographic insights and policy implications. International Journal of Care and Caring, 3(3), 323-337, https://doi. org/10.1332/239788219X15488381886380

Filgueira, C.H y Fuentes, A. (1999). Vulnerabilidad, activos y recursos de los hogares: una exploración de indicadores. Montevideo, Uruguay: CEPAL.

Fordham, M., Lovekamp, W. E., Thomas, D. S. y PhiIlips, B. D. (Ed.) (2013). Understanding social vulnerability. Social vulnerability to disasters. (pp.129). CRCPress. New York, USA: Taylor and Francis Group.

García Ballesteros, A., Jiménez Blasco, B. C. (2016). Envejecimiento y urbanización: implicaciones de dos procesos coincidentes. Investigaciones geográficas. Boletín del Instituto de Geografía, (89), 58-73, https://doi.org/10.14350/rig.47362

Garcia-Coll, A., López-Villanueva, C. y Pujadas, I. (2016). Movilidad residencial en tiempos de crisis. El caso de la Región Metropolitana de Barcelona. Scripta Nova: Revista Electrónica de Geografía y Ciencias Sociales 2016, 20, 549(04), https://doi. org/10.1344/sn2016.20.17205

Gómez, JM. y Hernández Aja, A. (2021). El Atlas de la Vulnerabilidad Urbana en España: objetivos resultados y retos de futuro. Revista Papers, 63, 20-36.

Gumà, C. y Fernández-Carro, C (2021). Life goes on: The influence of the perceived quality of social relations on older women's mental health after the loss of a partner in Europe. Aging \& Mental Health, 25 (1) 53-60, https://doi.org/10.1080/13 607863.2019.1675141

Hammel, E.A. y Laslett, P. (1974). Comparing Household Structure Over Time and Between Cultures. Comparative Studies in Society and History, 16, 73-109, https://doi.org/10.1017/S0010417500007362

Kaztman, R. (2000). Notas sobre la medición de la vulnerabilidad social. Notas sobre la medición de la vulnerabilidad social. Documento de trabajo del IPES. Colección Aportes Conceptuales, 2. Universidad Católica del Uruguay.
Kreyenfeld, M. y Konietzka, D. (2017). Analyzing childlessness. En Kreyenfeld, M.; Konietzka, D. (Eds.). Childlessness in Europe: Contexts, causes, and consequences (3-15). Rostock, Alemania: Springer.

Leal, J. (2010). La formación de las necesidades de vivienda en la España actual. En J. Leal, (ed.). La política de vivienda en España. Madrid, España: Ed. Pablo Iglesias.

Leal, J. y Martínez del Olmo, A. (2017). El progresivo abandono de la política de vivienda en España. Cuadernos de Relaciones Laborales, 35 (1), 15-41, http://dx.doi.org/10.5209/CRLA.54982

Lebrusán Murillo, I. (2019). La vivienda en la vejez: problemas y estrategias para envejecer en sociedad. La vivienda en la vejez. Madrid, España: Politeya CSIC.

Lechuga, M. L., Martínez, Ú. F. y Carmona, A. L. (2011). Medidas y caracterización de la vulnerabilidad a la exclusión social de los hogares en España. Rect@: Revista Electrónica de Comunicaciones y Trabajos de ASEPUMA, (12), 53-68.

López-Villanueva, C. (2008). Famílies a Barcelona: diversitat, dinàmiques i estructures. Barcelona Societat, 15, 5-24. Ed. Ajuntament de Barcelona.

López-Villanueva, C. y Pujadas, I. (2011). Transformaciones sociodemográficas y territoriales de los hogares unipersonales en España. Boletín de la Asociación de Geógrafos Españoles,55, 153-182.

López-Villanueva, C. y Pujadas, I. (2018a). Vivir solo en España. Evolución y características de los hogares unipersonales en la vejez Panorama Social, 28, 93115.

López-Villanueva, C. y Pujadas, I. (2018b). La evolución de los hogares unipersonales en España. Contrastes entre áreas rurales y urbanas en el umbral del s.XXI. En F. García-González (ed.). Vivir en soledad. Viudedad, soltería y abandono en el mundo rural (España y América Latina, siglos XVI-XXI (205238). Madrid, España: Iberoamerica Vervuert.

López-Villanueva, C., Pujadas, I. y Rubiales, M. (2019). Hogares unipersonales y curso de vida: diversificación por edades y concentración espacial en las regiones urbanas de Madrid y Barcelona. Estudios Geográficos, 80 (287), https://doi.org/10.3989/ estgeogr.201929.009

McHugh, M. L. (2013). The chi-square test of independence. Biochemia medica, 23(2), 143-149, https;//doi.org/10.11613/BM.2013.018 
Meslé, F. (2006). Recent Improvements in Life Expectancy in France: Men are Starting to Catch Up. Population (61) 4, 365-387.

Mitchell, J.M. y Kemp, B.J. (1996) The Older Adult Disability Scale: Development and validation. Rehabilitation Psychology, 41(3), 180-203, https://doi. org/10.1037/0090-5550.41.3.187

Módenes, J.A. y López-Colas, J. (2014). Cambio demográfico reciente y vivienda en España: ¿hacia un nuevo sistema residencial?. REIS. Revista de Investigaciones Sociológicas, 148, 103-134, https:// doi.org/10.5477/cis/reis

Pérez Díaz, J.; Abellán A. (2018). Envejecimiento demográfico y vejez en España. Panorama social, 28, 11-47.

Perona, N. y Rocchi, G. (2001). Vulnerabilidad y exclusión social. Una propuesta metodológica para el estudio de las condiciones de vida de los hogares. Kairos. Revista de Temas Sociales, 8(8).

Pujadas I., Bayona-i-Carrasco, J., Gil-Alonso F. y López Villanueva, C. (2013). Pautas territoriales de la fecundidad en la Región Metropolitana de Barcelona (1986-2010). Estudios Geográficos, 74, (275), 585-609, https://doi.org/10.3989/estgeogr.201321

Pujadas, I. (2009). Movilidad residencial y expansión urbana en la Región Metropolitana de Barcelona, 1982-2005. Scripta Nova: Revista Electrónica de Geografía y Ciencias Sociales, 13 (290).

Pujadas, I., Bayona-i-Carrasco, J. y Rubiales, M. (2016). Movilidad residencial en edades avanzadas en España. Una perspectiva metropolitana. Finisterra, 102, 121-142, https://doi.org/10.18055/finis4250

Reher, D., Requena, M. (2017). Elderly women living alone in Spain: the importance of having children. European Journal of Ageing, 14 (3), 311-322, https://doi.org/10.1007/s10433-017-0415-6

Reher, D., Requena, M. (2018). Living alone in later life: A global perspective. Population and Development Review, 44 (3), 427-454, https://doi. org/10.1111/padr.12149

Rogero, J. (2015). Personas mayores y familia. En Torres Albero, C. (Ed.), España 2015. Situación Social (374-381). Madrid, España: CIS.

Rojo-Pérez, F., Fernández-Mayoralas, G. y Lardiés-Bosque, R. (2012). Entre las necesidades y las oportunidades de las familias para el cuidado de sus mayores que envejecen en casa. En V.Rodríguez (ed.). Inmigración y cuidados de mayores en la Comunidad de Madrid. (217-308). Madrid, España: BBVA

Ruiz Rivera, N. (2012). La definición y medición de la vulnerabilidad social. Un enfoque normativo. Investigaciones geográficas, 77, 63-74.

Ruiz, E. et al. (2020). Índex de vulnerabilitat social a la Regió Metropolitana de Barcelona, 2020. Barcelona, España: Estudis territorials. Àrea de desenvolupament de polítiques urbanístiques.

Sánchez González. D. (2009). Geografía del envejecimiento vulnerable y su contexto ambiental en la ciudad de Granada: Discapacidad, dependencia y exclusión social. Cuadernos geográficos de la Universidad de Granada, 45 (2), 107-135, https://doi. org/10.30827/cuadgeo.v45i0.759

Spielman, S. E., Tuccillo, J., Folch, D. C., Schweikert, A., Davies, R., Wood, N., y Tate, E. (2020). Evaluating social vulnerability indicators: criteria and their application to the Social Vulnerability Index. $\mathrm{Na}$ tural Hazards, 100(1), 417-436, https://doi. org/10.1007/s11069-019-03820-z

Sundström, G., Jegermalm, M., Abellán, A., Ayala, A., Pérez, J., Pujol, R. y Souto, J. (2018). Men and older persons also care, but how much? Assessing amounts of caregiving in Spain and Sweden. International Journal of Ageing and Later Life, 12(1), 7590, https://doi.org/10.3384/ijal.1652-8670.17356

Universidad Carlos III (2018). Metodología para la elaboración del índice de vulnerabilidad territorial de barrios y distritos de Madrid y ranking de vulnerabilidad. Área de coordinación y cooperación público social. Madrid, España: Servicio de Estudios y Evaluación Territorial.

Van de Kaa, D. J. (1987). Europe's second demographic transition. Population bulletin, 42 (1), 1-59.

Villa, M., y Rodríguez Vignoli, J. (2002). Vulnerabilidad sociodemográfica: viejos y nuevos riesgos para comunidades, hogares y personas. Santiago, Chile: CELADE, CEPAL.

Weinstein, N., Legate, N., Ryan, W. S. y Hemmy, L. (2019). Autonomous orientation predicts longevity: New findings from the Nun Study. Journal of personality, 87 (2), 181-193, https://doi.org/10.1111/ jopy.12379

Zamora López, F., Barrios, L., Lebrusan, I., Parant, A. y Delgado, M. (2017). Households of the elderly in 
Spain: Between solitude and family solidarities. In Ageing, Lifestyles and Economic Crises (pp. 135148). Nueva York, USA: Routledge.
Zueras, P. y Rentería, E. (2021). La esperanza de vida libre de enfermedad no aumenta en España. Perspectives Demogràfiques, 22, 1-4. 